\title{
NOTAS SOBRE UNOS FUNDAMENTOS PARA UNA NUEVA TEORÍA ECONÓMICA. CRÍTICA DE F. AZCURRA Y RÉPLICA DEL AUTOR
}

\author{
Antonio Mora Plaza \\ Economista, Madrid
}

\author{
Notes for a new theory economic. Critique from F. Azcurra and an \\ replicate from A. Mora
}

\begin{abstract}
In the Nómadas revue were published two notes from Antonio Mora Plaza for a fundamental new possible theory economic from Piero Sraffa. This notes were answered for Fernando Hugo Azcurra under a Marxian perspective. More late Antonio Mora Plaza wrote also an answer in two articles under a Sraffian view, but an heterodox view also under into an Sraffian traditional view. This revue bring in here for ours readers theses five mentioned articles.
\end{abstract}

Keywords: Sraffa, Marx, surplus, surplus value, prices, transformation

JEL: B51

\section{Introducción}

Este trabajo comprende 5 artículos. Los dos primeros ya han sido publicados en esta revista. Al primero de ellos respondió Fernando Hugo Azcurra economista y director de la revista Circus, de la U. de Buenos Aires- desde un punto de vista marxista. Ello me permitió abordar el tema de los fundamentos, de la necesidad de unos nuevos fundamentos de la economía, pero ya no sólo desde la crítica a la teoría convencional neoclásica-marginalista, que es la que ha triunfado en la enseñanza a pesar de su incoherencia, de su puerilidad y de su nula capacidad explicativa (de la crisis, los ciclos, por ejemplo), sino también de las diferencias y semejanzas de estos nuevos posibles fundamentos de raíz esrafiana y el canon marxista. ¿Son sustitutivos o complementarios? ("Sraffa y la teoría del excedente"). También se abordan tres temas concretos: la teoría del valor-trabajo de Marx, la teoría de la explotación y la transformación de valores a precios, pero a partir de un modelo de fundamentos esrafianos. Esto especialmente en el último artículo ("Marx desde Sraffa"). En éste se han utilizado inevitablemente las matemáticas con el fin -otra cosa es el resultadode discutir de teoría económica (análisis) y no de construir un modelo matemático con relleno de conceptos económicos (tal y como es el equilibrio competitivo marginalista dejado de la mano de Walras). Ahora se comprende por qué traemos a colación de nuevo los dos primeros artículos: para que el lector los tenga a la vista y pueda seguir la crítica de F. Azcurra, que es el tercero de ellos ("Sraffa y la metafísica de la economía"). Al final será el lector será juez, pero lo que importa no es el resultado de la contienda intelectual, 
sino los argumentos aportados. Aquí no hay veredicto, ni vencedores, ni vencidos.

\section{Notas para los fundamentos de una nueva teoría económica a partir de Sraffa (I parte)}

\section{Antonio Mora Plaza}

Esta crisis, al igual que la del año 29 del siglo pasado, ha dejado para el arrastre gran parte de la teoría económica actual, en especial la microeconomía; también la teoría de las expectativas racionales y la de los mercados eficientes. Las recomendaciones sobre desregulación de los mercados y del sistema financiero más la especulación como expresión del egoísmo de los individuos no nos ha llevado al mejor de los mundos posibles sino al peor. El principio de la mano invisible que nos han traído los creyentes en las supuestas virtudes de las asignaciones eficientes y la flexibilidad de precios y rentas se ha mostrado tan falso como equivocadas las políticas económicas surgidas de estos principios para sostener el empleo. Quizá no esté en estos fundamentos el origen de la crisis, pero las políticas adoptadas inspiradas en ellos han demostrado su fracaso. Por ello es urgente unos nuevos principios, unos nuevos fundamentos, unos nuevos esquemas de pensamiento -podemos llamarlos nuevamente paradigmas- que nos traigan nuevos análisis, nuevas políticas, nuevas soluciones, porque todo los neoclásico-marginalista ha fracasado. También la macro prekeynesiana dominante, que ha devenido en una mera contabilidad, en una enfermiza obsesión por reducir el déficit cuando lo que hay que reducir es el paro, y la realidad está demostrando que acabar con el primero no lleva a acabar con el segundo, sino más bien lo contrario. Por todo ello, algunos -una minoría, un puñado de heterodoxos- defendemos el desarrollo de unos nuevos y alternativos esquemas de pensamiento para modificar para bien esa cosa que llamamos realidad económica. Los heterodoxos son -somos- pocos y de escuelas diferentes: keynesianos, marxianos, esrafianos, ricardianos, etc. Lo que aquí se propone es el desarrollo de unos nuevos fundamentos a partir de Sraffa y, en concreto, a partir de su corto pero singular y extraordinario -dicho también en sentido literal- libro Producción de mercancías por medio de mercancías. Sólo a partir -porque su obra no es suficiente per se para una alternativa a los esquemas marginalistas y/o prekeynesianos actuales- de lo escrito por el turinés es, en mi opinión, una semilla saludable para unos nuevos fundamentos de una nueva teoría y política económica. ¿Cuáles son esas características y esas diferencias respecto a la/s teoría/s imperantes actuales? Veámosla de forma esquemática:

1) Sraffa parte de la realidad, de toda la realidad. Probablemente eso sólo pueda decirse de los fisiócratas, con Quesnay y su "Tableau" a la cabeza", de Walras con su modelo de equilibrio general y de Marx, aunque Marx es algo más que un economista. Frente a los modelos neoclásicos de Marshall del

\footnotetext{
${ }^{1}$ Tenemos en español La Fisiocracia, de R. L. Meek, 1975, edit. Ariel (The Economics of Phisiocracy, 1962).
} 
equilibrio parcial de empresas, sectores y mercados; frente a los modelos explicativos marginalistas previos a Walras, el modelo de Sraffa no sólo parte de toda la realidad, sino que toma los datos de ella directamente. ¡No puede haber mayor realismo en un modelo! Y sin embargo, no por ello lo de Sraffa ${ }^{2}$ en "Producción ..." deja de ser un modelo, al igual que lo son todas las explicaciones que tienen la realidad como espejo, incluido el mismísimo El Capital de Marx, con sus más de 2000 páginas. La ciencia -o lo que se reputa como tal, lo que tiene tal pretensión- no deja de ser un modelo. Y eso es así desde el primer gran modelo con pretensiones de cientificidad creado por la mano del hombre, Los elementos de Euclides, hasta llegar a los misterios de la mecánica cuántica y su pretensión de llegar a una teoría del Todo (S. Hawking $^{3}$ ). Sraffa parte del conjunto de todos los medios de producción, de todos los productos finales, de todos los precios y de todos los inputs de trabajo. Hace excepción con las dos variables que son, en realidad, objeto de su trabajo: salarios y ganancias, es decir, del conjunto del excedente. Sraffa reduce en su modelo los salarios y ganancias a una sola tasa de ganancia y a una sola tasa de salario. No hay mayor problema para generalizarlos y tomar salarios y ganancias de la realidad. Por supuesto que todos estos datos han de ser agrupados, agregados, para simplificar los cálculos, pero sólo para eso, para que podamos manejarnos mejor, con cierta eficacia. En realidad los datos de que parte Sraffa son los mismos -agrupados o agregados de otra forma- de los que parte Leontief y sus tablas Input-Ouput. Curioso que ambos emplearan un instrumental matemático similar y no se tiene constancia de que cruzaran alguna vez una palabra, oral o escrita.

2) Sraffa coloca el tema del excedente en el centro de su sistema. Ricardo lo hizo con la distribución, Marx con su teoría de la explotación o plusvalía y los marginalistas con la asignación de los factores y determinación de precios. El excedente es lo que le queda de la producción tras reponer los medios de producción en un período para volver a comenzar el ciclo productivo en el siguiente. No se para el italiano a definir exactamente los sujetos sociales a los que se destina; tampoco las relaciones sociales que hay establecidos entre ellos. Esa tarea ya lo hicieron sus predecesores clásicos y Marx. Ese trabajo ya estaba hecho, para qué repetirse.

3) La macro y la micro abordan eso que se llaman fenómenos económicos desde dos puntos de vista, bajo dos perspectivas. La macro estudia el conjunto de los fenómenos, el bosque de los fenómenos, como tal conjunto, con apenas unas variables que lo retratan: producción agregada, renta, consumo, exportaciones, importaciones, ingreso público, gasto público, salarios, empleo, etc.; por el contrario, el objeto de la micro ${ }^{4}$ es la empresa, el sector como

\footnotetext{
${ }^{2}$ Sobre la vida de Sraffa está el clásico de Jean-Pierre Poitier en Edicions Alfons el Magnamim (traducido) y el de Roncaglia (sin traducir). El primero es más biográfico que intelectual; lo contrario el segundo. Por cierto, Alessandro Roncaglia tiene el mejor libro de la historia del análisis económico que yo haya leído, incluido el Schumpeter: La riqueza de las ideas, publicado en el 2001 en italiano y traducido en el 2005 al inglés y un año más tarde al español.

${ }^{3}$ El gran diseño, 2010. Dice el físico inglés que "adoptaremos una posición que denominamos realismo dependiente del modelo" (pág. 13).

${ }^{4}$ Me gusta poner de ejemplo el libro de Hal R. Varian Microeconomía intermedia, 2003 (Intermediate Microeconomics. A Modern Approach, 1999). Es un libro didáctico, pleno de los tópicos marginalistas. Se utiliza mucho en la facultades de economía.
} 
agregado de empresas y/o productos y el mercado como ente -no sé como llamar algo que físicamente no existe como tal- donde supuestamente se forman los precios. Pues bien, el modelo de Sraffa estudia justamente lo que hay en medio, el conjunto de todas las empresas y de los bienes y servicios en su mutua interdependencia. $Y$ eso tiene efectos prácticos y consecuencias teóricas que no acogen ni la macro ni la micro. Es verdad que para superar este inmenso hiato se ha inventado la teoría del equilibrio general por Walras, Debreu, Arrow, etc. ¿Pero es la teoría del equilibrio general algo más que los teoremas del punto fijo de Brower y Kakutani con conceptos económicos? ¿Es realista esta teoría? ¿Ha superado los problemas de la existencia de rendimientos crecientes, la de bienes públicos, los efectos externos, la información asimétrica e insuficiente, la competencia imperfecta, la existencia de los monopolios, los oligopolios? ¿Es la teoría del equilibrio general una teoría que explica la realidad o un teoría de cómo la realidad nos gustaría que fuera? ¿Están resueltos los problemas de existencia, unicidad y estabilidad del equilibrio más allá del plano teorético? Lo dejo en el aire ${ }^{5}$. En el modelo de Sraffa la interdependencia es fundamental para establecer relaciones entre las variables monetarias del sistema: precios, ganancias y salarios, y no siempre un aumento de una lleva necesariamente la disminución de la otra, precisamente porque resultan fundamentales las relaciones entre medios de producción y trabajo de los diversos sectores objetos de comparación, de los que suministran medios a estos y de todos los sectores de la economía trasladados en el tiempo; también porque resultan determinantes estas relaciones para el sector cuyo producto tomamos como numerario.

4) Los precios. Para el marginalismo los precios tienen que ver con esa cosa que en los manuales de economía llaman costes marginales. Según eso, los gestores de las grandes empresas así como la vendedora de castañas que luego veremos, fijan los precios de acuerdo con los costes marginales incorporados a los costes totales por la última unidad producida o vendida ( ila última castaña del día!), aunque no tengan ni idea ni hayan oído hablar nunca de esa cosa llamada ... marginal y menos aún sepan calcularla. Eso es lo ideal, pero entonces, ¿de qué hablamos? ¿De cómo se forman los precios en la realidad o de cuál sería el ideal de formación de los precios para otros fines, como por ejemplo ... una supuesta eficiente asignación de los recursos? ¿Estamos en lo positivo o en lo normativo? Pues es así como te lo cuentan en todas las facultades del mundo, en todos los manuales ortodoxos, desde el de Marshall (Principios de Economía) de hace 120 años hasta el de Samuelson (Economía) que aún se estudia. Parte Sraffa de algo muy distinto y que hacen todos los comerciantes y empresarios de todo el mundo: añadir un margen a los costes para obtener los precios de venta. Esa es la tasa de ganancia de Sraffa, no obstante su generalización a tantas tasas como bienes y servicios producidos/vendidos como se quiera, como queda dicho, no tiene mayor problema.

\footnotetext{
${ }^{5}$ El que quiera aterrizar un poco sobre estos temas, pero vistos desde la trinchera marginalista, tiene el libro de Julio Segura Análisis microeconómico, 2004, Alianza Universidad Textos. En cuanto a la historia del equilibrio económico a partir de Walras, véase en la red Una larga polémica: el tatônnement walrasiano, del mismo autor. http://www.aehe.net/publicaciones/ihe/archivos/ihe2/AR_03_Segura_Julio_N2_Pp75-104.pdf
} 
5) Sraffa anuncia en el comienzo de su libro que no hace ningún supuesto sobre ningún tipo de rendimientos. Dicho así parecería al profano que eso es algo meramente técnico, acreedor de su atención sólo por los especialistas, por los economistas y no todos. Pues nada de eso, porque forma parte del núcleo duro de la pretendida fundamentación del análisis económico de raíz esrafiana. Que no se haga ninguna hipótesis en los rendimientos supone que el modelo esrafiano trabaja con una libertad sobrecogedora, porque no considera vital para esos fundamentos la relaciones reales e insoslayables entre los medios de producción que se emplean y los productos finales que se obtienen. Eso no significa que no se pueda concretar el modelo estableciendo esas relaciones y no por ello dejará de ser necesariamente merecedor el modelo que surja del calificativo de esrafiano, pero con una salvedad: siempre que salarios y ganancias no vengan determinados por condicionantes técnico-productivos, siempre que uno depende del otro. No obstante, quisiera hacer la pregunta a los estudiosos de Sraffa: ¿esta liberalidad esrafiana, esta negación de cualquier tipo de relación implícita en el modelo entre medios y productos, puede se mantenida a lo largo de todo el libro de "Producción ..."? Queda en el aire.

6) Otra razón aún más importante que la anterior para ser acreedor "Producción..." de texto matriz de los fundamentos del análisis económico: para Sraffa el capital es sólo trabajo fechado. Ya ha salido a colación hace un suspiro, pero por otro tema. Aquí la diferencia con el marginalismo y lo neoclásico se ahonda hasta hacer incompatible un tipo de fundamentos con otros. El capital, es decir, el conjunto de los medios de producción que alguna vez han sido producidos, lo ha sido por obra de la mano del hombre y de la mujer. Ningún extraterrestre ha hecho el trabajo por nosotros, nadie nos lo ha regalado. Es algo tan de sentido común que cuesta explicar lo evidente, al igual que no hay que dar demasiadas explicaciones a las hipótesis en la geometría o, en general, en las matemáticas: las hacemos porque queremos, porque avizoramos finales interesantes, significativos, útiles, bellos estéticamente. Para el marginalismo y lo neoclásico, el capital entra como medio de producción en pie de igualdad con el trabajo, es un actor más de la producción, con sus derechos, sus esperas, sus penurias, sus escaseces y sus merecimientos. Y, claro está, merece una remuneración, una renta. Tiene además su destinataria clase social, claro. ¿Será por eso, por esta justificación ideológica, por lo que aún perdura ese marginalismo a pesar de los ataques merecidos y demoledores que ha sufrido por parte de los Robinson, Kaldor, Dobb, Sraffa, Garegnani, Pasinetti, etc.? ${ }^{6}$ Hay al menos tres modelos posibles, tres candidatos para los fundamentos del análisis económico -el marginalismo, el marxismo y el esrafismo- y los tres tienen su centro y gravitan en torno a esa cosa llamada capital: para el marginalismo es un factor más de producción, para el marxismo es una relación social, para el esrafismo es mero trabajo fechado. Intelectualmente -pero sólo intelectualmente- no hay color en mi opinión: lo de Sraffa es tan de sentido común que sólo puede ser atacado desde otro frente: el de la trivialidad. Ahora bien, el que ha triunfado en la enseñanza por diversos motivos, de los cuales ya hemos apuntado uno, es el marginalista.

\footnotetext{
${ }^{6}$ Un economista viajero como G.C. Harcourt recogió gran parte de la polémica sobre la teoría del capital en su libro Some Cambridge controversies in the Theory of Capital, 1975.
} 
7) $Y$ ahora viene otra pregunta capital en el intento de ubicar a Sraffa en el epicentro del análisis económico: ¿Si el objeto principal de estudio de Sraffa es el excedente, es decir, la suma de ganancias y salarios, cuáles son los fundamentos que llevan a un reparto y no a otro? Los marginalistas tienen una respuesta: las productividades marginales; Sraffa, simplemente, no tiene ninguna. Al menos implícita, pero es fácilmente deducible por omisión: la lucha de clases. Por supuesto que el italiano no menciona esa expresión en toda su obra ni nada que lleve a ella, pero permanece implícita. Pero tan es así que cualquier intento de ampliación y/o concreción del modelo esrafiano es permitido salvo el de que se haga endógeno al modelo el reparto del excedente entre salarios y ganancias: una variable ha de ser independiente y la otra dependiente. Puede hacerse por aquello de la libertad de expresión, pero el resultado que quede, por brillante que parezca, por explicativo que fuera, por contrastable que sea, tendrá todas estas cualidades, pero no será esrafiano.

8) No es sustancial al modelo de Sraffa la optimización en las decisiones de consumidores y productores. El marginalismo nos somete a la tiránica y titánica tarea de optimizar todas nuestras decisiones, al menos en lo que se refiere a la satisfacción de nuestras necesidades materiales. Según el marginalismo, cuando compramos el pan, alquilamos una casa, tomamos el autobús, adquirimos un bolígrafo, pedimos un trozo de tarta, vamos al cine, damos una propina, etc., obligamos a nuestro cerebro, a nuestra conciencia y -también- a nuestra paciencia, a optimizar, a calcular -supongo que intuitivamente- cuál es la satisfacción, la utilidad marginal que ello nos produce. No sé si Walras haría tales cálculos, pero al menos él era ingeniero, pero para el común de los mortales no me lo creo. Ni siquiera las decisiones empresariales. ¿Cuántos empresarios saben qué es eso de la productividad marginal?, ¿qué es eso de las relaciones de sustitución?, ¿qué es un coste marginal? Parece un dislate, verdad, pero esos son los fundamentos - microeconómicos- en los que se basa la economía ortodoxa actual, la que se estudia en las universidades, al menos a niveles de grado y licenciatura. Reconozco que es una simplificación lo que estoy diciendo, pero da más miedo cuando te lo explican y razonan, os lo puedo asegurar. En Sraffa no hay que optimizar, al menos de esta agobiante y agotadora manera. Hay en su modelo una excepción, pero sumamente importante, cuando se llega al capítulo de los métodos de producción o elección de técnicas. Allí hay que elegir -o es muy conveniente-, pero se hace entre alternativas tecnológicas/organizativas tomadas de dos en dos: ¡eso ya es otra cosa!

9) Cuando estudiaba economía en la facultad y me explicaban los fundamentos de la producción siempre me decían lo siguiente: supongamos una empresa que produce un bien o servicio ${ }^{7}$. Como cualquier estudiante yo cometía el error de tomar apuntes y aceptaba eso que me decían de una empresa-un producto, pero luego me iba a El Corte Inglés a comprar algo que supuestamente necesitaba y entonces me acordaba de lo que me habían explicado y me decía: ¿me habré equivocado de clase y me he metido en una para marcianos curiosos? Yo esperaba que eso de una empresa-un producto lo fuera a efectos

\footnotetext{
7 "La economía consiste de un elevado número de empresas perfectamente competitivas, cada una de las cuales produce el mismo único bien utilizando la misma función de producción", Thomas J. Sargent (Teoría macroeconómica, 1988; Macroeconomic Theory, 1979).
} 
pedagógicos y que alguna vez me explicarían un modelo más acorde con la realidad, vamos, el modelo "Cortelnglés", donde tenía a mano -aunque no de mi bolsillo- millones de objetos. Pues nada de eso ocurrió y acabé la licenciatura sin salir del modelo uno-uno. Un día por la calle -era inviernohacía frío y me encontré un puesto de castañas que sólo vendía castañas y compré un cucurucho del fruto del castaño a cambio de unas pesetas, la moneda de curso legal de entonces. Y luego pensé: jal fin una... empresa como las que me han explicado durante los cinco años de carrera! Sí, la teoría económica convencional, en sus fundamentos, es una teoría para castañeras. Lo peor es que cuando intenté preguntar a la castañera si la cantidad de castañas que vendía resultaba de igualar el precio que pedía con el coste marginal de la última castaña vendida me arrepentí: ¡Cinco años de estudio y no me servían ni para entablar una conversación económica sobre los fundamentos de la existencia económica de la castañera! Sraffa empieza con la producción simple, es decir, también con un modelo a lo castañera, pero con todos los oficios y productos insertos en el modelo, es decir, con mucho tipo de empresas distintas, aunque vendiendo una sólo tipo de producto. Algo es algo. Además, pasada la primera mitad del libro, arribamos a las tumultuosas aguas de la producción conjunta, donde una empresa puede producir múltiples mercancías -hoy diríamos bienes y servicios- y donde un mismo producto puede ser producido por cualquier número de empresas. ¡Esto ya es otra cosa! $Y$ esto $-y$ es fundamental- está en los fundamentos, no en las cúspides del equilibrio general walrasiano o de cualquier otro tipo, autor o estudio de esos que sólo lo escuchan los tribunales para la adquisición del título de doctor u oposiciones a cátedra. La producción conjunta tiene sus problemas, es verdad, pero nadie ha dicho que sea fácil eso que se llama desde Walras en economía teoría pura.

Y en mi opinión -discutible, como cualquier opinión- hemos acabado con los fundamentos del análisis esrafiano de la economía. Hay más conceptos en Sraffa, como los de la razón-patrón, la mercancía-patrón, la diferenciación entre bienes básicos y no básicos, el desplazamiento de los métodos de producción (hoy, elección de técnicas), el del capital fijo, las mercancías que se autoreproducen. Son convenientes o no según gustos u opiniones, pero sólo son en mi opinión- esenciales las cosas que se han explicado anteriormente: la realidad como fuente de datos, el excedente como objeto de análisis, las relaciones de interdepencia entre sectores, la formación de los precios a partir de un margen sobre los costes, los supuestos sobre los rendimientos, el capital como trabajo fechado, la lucha de clases o conflictos sociales para el reparto del excedente, la no necesaria optimización en la toma de decisiones y la producción conjunta. Estas podrían ser las notas distintivas de unos posibles fundamentos económicos de raíz esrafiana.

A pesar de lo anterior, nos podemos preguntar cuáles serían las características de un modelo para que pudiera ser tildado, motejado, de esrafiano, pregunta distinta de la anterior que ya hemos visto que se refiere a los fundamentos del análisis esrafiano. Pues bien, para mí sólo son dos: el excedente como objeto de análisis y el reparto exógeno del mismo, es decir, por los conflictos o la lucha de clases. De hecho podría darse la siguiente definición de qué es la economía según Sraffa: es el estudio del excedente, de sus límites y de su 
reparto. Por supuesto que Sraffa nunca lo expresó de esa manera porque era muy pudoroso o quizá porque no lo consideró necesario, ni importante, ni oportuno.

La importancia de Sraffa intelectualmente -pero de momento sólo intelectualmente, porque no ha llegado a los manuales- es que cambia los paradigmas de los fundamentos del análisis económico, tal y como hemos visto. Y no sólo una pieza, sino que es todo el puzzle, es un nuevo entramado lógico-económico lo que nos ofrece a partir del cual se puede completar la panorámica, hacer más nítido ese espejo borroso que son los fundamentos de una nueva ciencia, forma de conocimiento o expresión artística. Sobre la importancia de Sraffa en los fundamentos tengo una opinión personal que no pido sea compartida. En las áreas aludidas a veces una simple recolocación de las piezas del puzzle supone un hecho revolucionario, el nacimiento de una nueva visión, incluso de una nueva ciencia o forma de conocimiento o de expresión artística, como decía antes. Veamos algunos ejemplos. Euclides -o quien o quienes se escondan detrás de él- crean una forma de conocimiento abstracto -valga la redundancia- a partir de sólo cinco postulados. Esa forma de conocimiento tiene 2.300 años y aún se enseña. Copérnico, cambiando el paradigma del geocentrismo por el heliocentrismo, acaba con las complejas explicaciones basadas en ciclos y epiciclos, y con ello nace la ciencia de la astronomía relegando la astrología al campo de la creencia. Galileo pone en el centro de la física el movimiento -frente a la sustancia de Aristóteles- y junto con su ley de la inercia posibilita que Newton de a luz a la física clásica. Darwin y Wallace, con su criterio de evolución de las especies en función de su capacidad de adaptación al medio, dejan a Linneo y a todo la biología anterior en sus méritos taxonómicos. Con Freud el inconsciente es el responsable y motor de nuestros actos y no nuestra razón. El electromagnetismo se vuelve transparente en Faraday con la idea de campo (eléctrico y magnético), para que un matemático de alto nivel como Maxwell lo vuelva ciencia. Schrödinger, con su ecuación de onda ad hoc, responde indirectamente a los problemas del cuerpo negro y sienta las bases de la mecánica cuántica. Einstein, en 1905, aborda la aparente contradicción -no reconocida como tal hasta entoncesentre el principio de relatividad de Galileo y el hecho constatable de la constancia de la velocidad de la luz, y con ello crea la teoría de la relatividad.

Pues bien, Sraffa hace algo similar con los fundamentos microeconómicos marshallianos y marginalistas imperantes de la economía. Sitúa al excedente como objeto de la economía y no la formación de los precios; a los salarios y ganancias los saca del determinismo neoclásico para dejarlas caer en el campo de la lucha de clases, pero fijando sus límites, es decir, el propio excedente; a los efectos económicos, para lo que llamamos economía, lo importante es lo que se produce y cómo se distribuye, y no lo que se consume: éste es sólo un dato; Sraffa parte de una foto -aunque sea borrosa- de toda la realidad, del conjunto de relaciones intersectoriales de la economía y no de las empresas y mercados (microeconomía) o de sus agregados (macroeconomía); para el italiano las ganancias son un margen sobre los costes y no una retribución de un factor de producción (el capital) en pie de igualdad que otro (el trabajo); en su libro, los protagonistas son las mercancías (hoy bienes y servicios), los sectores y/o los procesos, y no las empresas o los consumidores; el capital es 
sólo trabajo fechado, un mero instrumento de trabajo que ya incorporó a su vez trabajo en su producción en el pasado, y no el centro de la teoría de la asignación de los recursos, como lo es para el marginalismo. En definitiva, Sraffa crea conceptos nuevos, pero también recoloca los de sus predecesores, especialmente los de los clásicos, y muy especialmente los de su referente máximo: David Ricardo.

No son sólo avances o -para algunos retrocesos- analíticos, incorporaciones al arsenal conceptual e instrumental del análisis, a la caja de herramientas de Robinson, sino una alternativa. Sraffa y el marginalismo son agua y aceite, no son combinables, no pueden vivir juntos en pie de igualdad. Bajo una perspectiva esrafiana, el marginalismo es una enfermedad infantil nacida a partir de la teoría de los rendimientos decrecientes en la agricultura (intensiva) de Ricardo más la visión del egoísmo smithiano como marco totalizador y como motor y matriz del comportamiento económico. El marginalismo es una infección en los ojos y en los huesos de la economía, que nace de una interpretación sesgada de los clásicos, arrancado con violencia intelectual a David Ricardo.

En mi opinión estas serían las notas características de unos nuevos fundamentos para un nuevo cuerpo teorético del conocimiento en lo que llamamos economía. Como todo, son discutibles, con diferente peso, quizá no únicos, seguro que deben ser completados con otros, pero encajados en estos, no superpuestos o amontonados. En Sraffa se echa de menos una teoría -una explicación- de la producción, del mercado y de la asignación de los recursos. Hay que trabajar en ello, pero por favor, nada de marginalismo, nada de absurdas asignaciones sobre supuestas productividades marginales, nada de niveles de producción basados en supuestos costes marginales, nada de relaciones de sustitución sobre supuestas decisiones racionales, nada de expectativas racionales, nada de falsos mercados eficientes. Nada de lo anterior tiene que ver con la realidad. Puede sonar bonito, puede dar títulos, doctorados, cátedras, pero todas esas cosas, todas esas construcciones mentales, son meras creencias, no han pasado la prueba de la realidad, ni en sus aspectos explicativos y menos aún, por lo visto hasta ahora, el qué hacer, la política económica para combatir las crisis, los ciclos, las desigualdades, el despilfarro de los recursos. La tarea está por hacer y ardua es, pero al menos tenemos la semilla: se llama Piero Sraffa.

Madrid, 22 de septiembre de 2011. 


\section{Tres notas sobre los fundamentos de una nueva teoría económica a partir de Sraffa ( $2^{\mathrm{a}}$ parte)}

\section{Antonio Mora Plaza}

En una nota anterior a esta relacionaba las notas de la economía que caracterizan el espacio económico intelectual abierto por Sraffa, donde el objeto de su análisis es el excedente ${ }^{8}$. Enunciaba y comentaba su economía en nueve notas. Pero aquello tenía un defecto: no estaban jerarquizadas y el análisis de una estructura de pensamiento exige al menos la jerarquía. Pongamos algún ejemplo antes de entrar en harina. Así, en el libro de Producción de mercancías por medio de mercancías no tienen el mismo peso a la hora de construir una alternativa a la teoría actual el capital como reducción a trabajo fechado que la distinción entre bienes básicos y no básicos; la formación de los precios a partir de un margen sobre los costes o la razónpatrón. Pero además esta jerarquía de las ideas, conceptos, paradigmas inventadas por Sraffa, hay que contemplarlas, en mi opinión, con perspectivas de futuro, en función de la capacidad del desarrollo de la estructura de pensamiento esrafiano y no sólo en función del lugar y peso que ocupan en su libro. Por ejemplo, el hallazgo -creo que es más hallazgo que invención- de la mercancía-patrón (standard commodity) para eliminar la influencia del valor de la mercancía que se usa como baremo para medir el resto de las variables de su sistema ocupa un lugar prominente en su libro cuando estamos en la reproducción simple. Fue una hazaña intelectual de máximo nivel; tanto como, por ejemplo, la ley de la inercia en Galileo, la idea de campo de Faraday o el principio de relatividad en Einstein. $Y$ sin embargo representa una rémora cuando se entra en el análisis de la producción conjunta a pesar de los esfuerzos de Sraffa -o precisamente por esos esfuerzos- por hallar el equivalente en ese capítulo. Puestos estos ejemplos, paso a lo que considero las tres características sin las cuales una construcción analítica sobre lo que entendemos por economía no podría tildarse de esrafiana:

1) La primera y principal, la que constituye el núcleo duro de su teoría, es el grado de libertad que hay en el reparto del excedente entre salarios y ganancias. Es más la resultante de su esquema de pensamiento que una hipótesis previa. Que Sraffa diera este paso, que llegara a la necesidad de esta conclusión demuestra su genio, porque cualquier otro aspecto de su teoría podía ser asimilada, domesticada por el marginalismo. Así, la distinción entre bienes básicos y no básicos tiene su equivalente clásico en la distinción entre bienes de primera necesidad y otros de lujo, y no es refractario al marginalismo y a los neoclásicos esta última distinción porque ese puente, esa ilación en la historia del análisis económico lo ocupa Marshall; el manido tema de los rendimientos, si constantes o no, está presente en el análisis Input-Output de Leontief, que es un caso especial de la relación capital-trabajo neoclásico y de sus curvas convexas, y también lo está en Von Neumann; incluso la teoría del

\footnotetext{
${ }^{8}$ Y ya aquí, en el mismo objeto del análisis, comienzan las diferencias insalvables entre lo neoclásico-marginalista y lo esrafiano, porque para aquélla la economía es el "estudio el comportamiento humano como una relación entre fines, por un lado, y medios escasos con usos alternativos, por otro", según la conocida definición de Lionel Robbins.
} 
capital como trabajo fechado forma parte de la teoría de las amortizaciones y del capital como actualización de rendimientos futuros; o como teoría de la preferencia temporal en Böhm-Bawerk, o la perspectiva intertemporal en Hicks. En definitiva, tiempo y capital no son precisamente una extraña pareja en las concepciones neoclásicas y/o marginalistas. Pero lo que no puede asimilar lo neoclásico-marginalista es que haya una relación entre tasas de salarios y ganancias que no haya sido rota por otras relaciones de otros elementos con cada una de ellas, porque eso supone la ausencia de una justificación de la retribución de los factores determinada por las condiciones de la producción; supone introducir la lucha de clases en el núcleo duro de la teoría, al igual que Marx con la teoría de la explotación (plusvalía). La diferencia con Marx es que, en mi opinión, la teoría de la plusvalía es una hipótesis del modo de producción capitalista que no pasa de una mera definición, que se enfanga en la arena del popperismo al no cumplir el requisito de falsibilidad de éste; en cambio, el grado de libertad entre salarios y ganancias preside, estructura y concluye todo su esquema, es a la vez basamento, espacio, estructura y techo de toda la arquitectura intelectual de Producción de...

2) El segundo aspecto en jerarquía es sin duda la determinación de los precios a partir de un margen sobre los costes. En el marginalismo, como es sabido, se determina sobre las supuestas productividades de los factores. La cosa no puede ser más descabellada y peregrina, incluso si nos movemos en un mero espacio normativo, porque para llegar a ello hay que hacer supuestos que nada tienen que ver con la realidad: competencia perfecta en todos los mercados presentes y futuros, ausencia de rendimientos crecientes (costes decrecientes), ausencia de bienes públicos, información perfecta para todos los actores económicos, ausencia de efectos externos, ausencia de organizaciones sindicales, etc. Alicia en el País de las Maravillas es un relato histórico, es puro historicismo comparado con el trivial y falso cuento de hadas de las productividades marginales. Un sueño del que aún no ha despertado el análisis económico del tiempo presente. De ese sueño se alimentan cátedras y nóbeles actualmente. No es sin embargo sustancial si los salarios se pagan post-factum -como propone Sraffa- o pre-factum, es decir, sobre todos los costes, incluyendo los salariales, como yo creo que hay que hacerlo en aras del más puro realismo. Es verdad que Sraffa trabaja con tasas unitarias de salario y ganancia, pero eso lo hace por dos motivos: por puro didactismo y porque trabaja con un modelo a largo plazo donde la competencia tiende a igualar los diferentes márgenes. No hay ningún problema con pasar de esas tasas unitarias a multitud de ellas en aras precisamente de ese realismo, aunque ello complique formalmente -pero sólo formalmente- los desarrollos del mundo intelectual económico abierto por el genial turinés.

3) El tercer y último basamento, la tercera pata que permite sostener todo el entramado esrafiano, es la consideración del capital como trabajo fechado, a diferencia de Marx, por ejemplo, que es una relación social en el mundo de la empresa, y a diferencia de Marshall, que recoge de Adam de Smith la idea del capital de una persona como "aquella parte de sus existencias de la cual espera obtener una renta"9. Es decir, para la economía imperante cuando

\footnotetext{
${ }^{9}$ Principios de Economía, (Principles of Economy), pág. 97, Editorial Síntesis, S.A., 2005.
} 
escribe Sraffa su obra, el capital se caracterizaba por sus efectos y no por su naturaleza; luego vino la aportación ya mencionada de Hicks; anterior a Sraffa la de Böhm-Bawerk, etc. Obsérvese que con el grado de libertad entre salarios y ganancias eliminaba Sraffa cualquier concepción técnico-productivista del reparto del excedente; ahora, con la eliminación del capital como entidad en pie de igualdad con el trabajo, elimina la justificación de su retribución al eliminar al actor de su espacio económico; con el grado de libertad se elimina la función, con la reducción a trabajo fechado se elimina al intérprete. El capital es trabajo, fechado, trabajo del pasado, pero sólo trabajo, del que sólo es un problema técnico -la actualización- la agregación de su uso en el presente para determinar los precios. Y mientras a los humanos no nos lluevan del cielo, sea el de Dante o el de Asterix, o mientras no nos lo regalen supuestos extraterrestres, los medios de producción, las instalaciones, los útiles, las materias primas, es decir, el capital o medios de producción han sido producidos alguna vez en el pasado por la mano del hombre (y de la mujer). Esa concepción pre-esrafiana del capital la dejó herida de muerte Joan Robinson cuando preguntó aquello de "en qué unidades se mide"10; Sraffa lo remató con el trabajo fechado.

Estas son, en mi opinión, las notas esenciales en la construcción intelectual de Sraffa. Ni siquiera el objeto de su análisis que es el excedente tiene tal fuerza persuasiva en su entramado, porque puede muy bien ser desbordado, explorarse otros territorios como son el comercio internacional, el crecimiento, la reproducción ampliada, las crisis, la demanda efectiva, incluso los ciclos, etc., a partir de los pilares asentados, enclavados por Sraffa, pero si en el curso de esos análisis no están presentes estas tres ideas cruciales de Sraffa, es decir, el grado de libertad en la distribución, el margen de ganancia sobre los costes y el capital como trabajo fechado, o están sustituidas estas ideas por otras cuando son necesarias y pertinentes su concurso, entonces el análisis podrá ser acertado o no, positivo o normativo, verificable o no, útil o fallido para el "qué hacer", pero no será esrafiano. Llevado al extremo de la caricatura, parecería la lucha por un adjetivo -esrafiano- una discusión escolásticamente trivial, una trampa nominalista, pero detrás de todo esto está lo de Althusser: la lucha de clases en la teoría, y esta no es escolástica.

Madrid, octubre de 2011.

\footnotetext{
10 The Production Function and the Theory of Capital, 1953/4. Aún en la década de 1950, cuando se publica el artículo de Joan Robinson, se pregunta ella en el mismo artículo de si "¿debe evaluarse este (el capital) de acuerdo con su capacidad de proporcionar ingresos en el futuro, o sus costes en el pasado?" Es decir, que no lo tenían muy claro. Era y es hoy día una patata caliente en manos de los neoclásicos de ahora, neoliberales en lo político.
} 


\section{Sraffa y la metafísica de la economía}

\section{Fernando Hugo Azcurra}

A propósito de una nota de Antonio Mora Plaza aparecida en la Revista digital Nueva Tribuna - Madrid el 4/11/2011.

- A.M. Plaza plantea la necesidad de desarrollar "nuevos y alternativos esquemas de pensamiento para modificar para bien esa cosa que llamamos realidad económica"

- Propone “... el desarrollo de unos nuevos fundamentos a partir de Sraffa y, en concreto, a partir de su corto pero singular y extraordinario libro "Producción de mercancías...".

- Sostiene que "Sólo a partir de lo escrito por el turinés -porque su obra no es suficiente per se para una alternativa a los esquemas marginalistas y/o prekeynesianos actuales- es, en mi opinión, una semilla saludable para unos nuevos fundamentos de una nueva teoría y política económica".

\section{Fundamentos del análisis de Sraffa en su obra "Producción..."}

\section{$\left.1^{\circ}\right)$ La realidad como fuente de datos}

"Sraffa parte de la realidad, de toda la realidad... no sólo parte de toda la realidad sino que toma los datos de ella directamente iNo puede haber mayor realismo en un modelo! ¿Cuál es esa realidad de la que parte Sraffa? “... el conjunto de todos los medios de producción, de todos los productos finales, de todos los precios y de todos los inputs de trabajo. Hace excepción con las dos variables que son, en realidad, objeto de su trabajo: salarios y ganancias, es decir, del conjunto del excedente" Estos son los datos de los que parte Sraffa y que son "los mismos -agrupados o agregados de otra forma- de los que parte Leontieff y sus tablas Input-output".

\section{$\left.2^{\circ}\right)$ El excedente económico es el centro de su sistema}

¿Qué es el excedente en Sraffa? “...es lo que le queda de la producción tras reponer los medios de producción en un período para volver a comenzar el ciclo productivo siguiente".

Sraffa "No se para a definir exactamente los sujetos sociales a los que se destina (el excedente); tampoco las relaciones sociales que hay establecidos entre ellos. Esta tarea “...ya lo hicieron sus predecesores clásicos y Marx. Ese trabajo ya estaba hecho, para qué repetirse".

\section{$\left.3^{\circ}\right)$ Interdependencia entre sectores}

"En el modelo de Sraffa la interdependencia es fundamental para establecer relaciones entre las variables monetarias del sistema: precios, ganancias y salarios, y no siempre un aumento de una lleva necesariamente a la disminución de la otra, precisamente porque resultan fundamentales las relaciones entre medios de producción y trabajo de los diversos sectores 
objetos de comparación, de los que suministran medios a éstos y de todos los sectores de la economía trasladados en el tiempo; también porque resultan determinantes estas relaciones para el sector cuyo producto tomamos como numerario".

\section{$4^{\circ}$ ) Formación de los precios.}

Para Sraffa los precios se forman a partir de lo que hacen "... todos los comerciantes y empresarios de todo el mundo: añadir un margen a los costos para obtener los precios de venta. Esa es la tasa de ganancia para Sraffa".

\section{$\left.5^{\circ}\right)$ Supuesto sobre rendimientos.}

Sraffa no hace ningún supuesto sobre ningún tipo de rendimiento. Pero esto no es algo meramente técnico "... forma parte del núcleo duro de la pretendida fundamentación del análisis económico de raíz sraffiana". El no hace ninguna hipótesis sobre rendimientos "...supone que el modelo sraffiano trabaja con una libertad sobrecogedora, porque no considera vital para esos fundamentos las relaciones reales e insoslayables entre los medios de producción que se emplean y los productos finales que se obtienen".

\section{$\left.6^{\circ}\right)$ El capital como trabajo fechado.}

¿Qué es el capital para Sraffa? "El capital es el conjunto de los medios de producción que alguna vez han sido producidos, lo ha sido por obra de la mano del hombre. Ningún extraterrestre ha hecho el trabajo por nosotros, nadie nos lo ha regalado. Es algo tan de sentido común que cuesta explicar lo evidente, al igual que no hay que dar demasiadas explicaciones a las hipótesis en la geometría o, en general, en las matemáticas: las hacemos porque queremos, porque avizoramos finales interesantes, significativos, útiles, bellos estéticamente".

\section{$7^{\circ}$ ) Distribución del excedente y conflicto social.}

¿Qué determina la distribución del excedente entre salarios y ganancias?

Sraffa no dice nada al respecto, pero está implícito: “... la lucha de clases. Por supuesto que el italiano no menciona esa expresión en toda su obra ni nada que lleve a ella, pero permanece implícita".

\section{$\left.8^{\circ}\right)$ Inexistencia de decisiones de maximización.}

"No es sustancial al modelo de Sraffa la optimización en las decisiones de los consumidores y de los productores".

\section{$\left.9^{\circ}\right)$ Producción conjunta.}

“... una empresa puede producir múltiples mercancías -hoy diríamos bienes y servicios- $y$ donde un mismo producto puede ser producido por cualquier número de empresas". 


\section{Sraffa versus Marginalismo}

1) $\mathrm{Ni} \mathrm{A}$. Marshall, con su equilibrio parcial de corto y largo plazo, ni los modelos explicativos marginalistas previos a Walras, parten de la realidad.

$\left.2^{\circ}\right)$ Los marginalistas no reconocen excedente alguno producido por la economía. Operan con lo que denominan asignación eficientes de los recursos y la determinación de los precios por los mercados en su movimiento de oferta y demanda.

$\left.3^{\circ}\right)$ No hay en Sraffa escisión entre micro y macroeconomía como en los marginalistas, describiendo la primera la empresa y el mercado, ocupándose la segunda de las variables agregadas: Consumo, inversión, exportaciones, ingreso público, gasto público, salarios, empleo, etc.

$4^{\circ}$ ) Para el marginalismo los precios son formados por los costos marginales incorporados a los costos totales. Nada de esto hay en Sraffa.

$\left.5^{\circ}\right)$ El marginalismo concibe rendimientos constantes a escala. Sraffa se desentiende de este presupuesto.

$6^{\circ}$ ) Para el Marginalismo el capital es un "factor" de producción equiparado a los otros dos: tierra y trabajo.

$7^{\circ}$ ) Lo que determina la distribución de lo producido entre los sectores sociales son sus productividades marginales. Para Sraffa no existe tal cosa.

$\left.8^{\circ}\right)$ Para el Marginalismo es sustancial la conducta maximizadora de los "agentes" en la toma de decisiones: consumidores maximizan funciones de utilidad, y productores maximizan funciones de ganancias (producción). En Sraffa no hay funciones para maximizar.

$9^{\circ}$ ) No existe tal cosa como: una empresa que produce sólo un producto o servicio tal como lo presenta el Marginalismo con sus costos y productividades marginales.

Es a partir de estas bondades y ventajas de la obra de Sraffa, en relación con las deficiencias de todo tipo que muestra el Marginalismo, que A.M.P. sostiene la necesidad de desarrollar "nuevos fundamentos" para una nueva teoría y una nueva política económica descartando definitivamente a la economía vulgar neoclásica.

\section{Sraffa y Marx}

Economía Política: tiene por objeto el análisis de las formas sociales de la producción de mercancías (K. Marx, "Grundrisse", Siglo XXI, Bs. as. 1971, II, p. 425) 
"El proceso capitalista de producción no es meramente producción de mercancías. Es un proceso que absorbe trabajo impago, que convierte los medios de producción en medios para succionar trabajo impago" (K. Marx, "Capítulo VI inédito", Ediciones Signos, Bs. As. 1971,p. 84).

"...los economistas burgueses, enredados en las ideas capitalistas, ven sin duda cómo se produce dentro de la relación capitalista, pero no ven cómo se produce esta relación..." (K. Marx, "Capítulo VI inédito", p. 106 y "Miseria de la Filosofía", S. XXI, p. 85).

10) "Sraffa parte de la realidad, de toda la realidad... El modelo de Sraffa no sólo parte de toda la realidad, sino que toma los datos de ella directamente iNo puede haber mayor realismo en un modelo!

a) No parte de la realidad;

b) No parte de toda la realidad;

c) No toma los datos directamente de ella;

a) Sraffa no parte de la vida activa y dinámica de los individuos que se relacionan y producen en la sociedad burguesa; no parte ni se propone penetrar e indagar ese movimiento histórico de las relaciones de producción dominado por el capital, del que las categorías no son sino la expresión teórica. Desde el momento en que sólo se quiere ver en esas categorías el aspecto puramente formal y cuantitativo, no hay que extrañarse, pues, que se caiga en un mundo abstracto. ¿Qué otra cosa es este modo lógico de proceder que borra a cada instante aquello que constituye las especificidades de un objeto hasta culminar en un concepto amplio, general, supuestamente vacío de sus "accidentes" y rasgos peculiares sin referencias sociales, históricas, particulares? ¿Qué otra cosa son "medios de producción"; "productos finales"; "precios"; "inputs de trabajo; "excedente", etc.?". Parte Sraffa, pues, no de las relaciones reales del capitalismo sino de sus expresiones teóricas que para él constituyen el resumen condensado de la "depuración" de los accidentes y rasgos que lo caracterizan, de modo que le permiten alcanzar su objetivo de una "economía como ciencia estricta".

b) No parte de toda la realidad. Parte de sólo el proceso de circulación del capital como reproducción y se dedica a un tema: el de la distribución del excedente como plusproducto entre salarios y ganancia. No examina lo determinante de la sociedad del capital: el proceso de producción a partir de la relación entre $\mathrm{Tw} / \mathrm{K}$, trabajo vivo/trabajo inerte, que no es sólo producción de mercancías, sino producción en una relación específica entre trabajo asalariado y capital, que en su movimiento produce y reproduce las relaciones sociales que lo sostienen y a sus portadores como clases antagónicas. (Cfr. Azcurra, F.H. "Plusvalor y Excedente", Ediciones Cooperativas, Bs. As. cap. 11).

c) Sraffa en ningún momento toma "los datos directamente de la realidad". Sraffa desarrolla un planteo teórico por lo que su análisis procesa datos que ya han dejado de ser tal para transformarse en conceptos ¿qué sino son "medios de producción"; "productos finales", etc.? No hay pues "mayor realismo en un modelo", el modelo ya no es "real" sino una simplificación abstracta. No es 


\section{esto lo censurable, sino que se lo quiera presentar como modelo que muestra su relevancia "empírica".}

$\left.2^{\circ}\right)$ El excedente es el centro de su teoría. Así es. Al deshacerse de los sujetos sociales, esto es, de quienes, cómo, en qué estructura de producción real se genera el excedente, puede dedicarse a considerarlo como el objeto "natural" central de la economía.

a) El excedente como categoría general muestra la lógica defectuosa (metafísica) de esta modalidad de pensamiento. Está definido como la producción de "la" economía en más del mínimo necesario para el reemplazo que deberá ser distribuido para poder recomenzar el ciclo en períodos siguientes. (Sraffa, "Producción..." p. 21). Al hacer abstracción de los rasgos específicos de las diferentes modalidades sociales de producir el excedente, llega al excedente como algo abstracto, al excedente puramente general y formal, pero como no puede desprenderse, a pesar de todo, de un contenido empírico, debe contener una referencia a su estado actual de excedente como producto de ésta sociedad en el momento de la distribución.

b) Ahora bien este excedente así definido no refleja las particularidades de ser excedente capitalista (plusvalor como plusproducto), tal modalidad de definición es asimilable a formaciones, esclavistas y feudales y de cualquier sociedad que produjera más de lo que necesita para la subsistencia. El excedente, desde el punto de vista de los valores de uso y/o consumo no es otra cosa que plusproducto, así considerado, es por tanto igual en todas aquellas sociedades. La particularidad en Sraffa está en su distribución bajo la forma de salarios y ganancias, pero sólo como eso: novedad distributiva. Lo principal es su "generalidad" como abstracción no su especificidad histórica.

c) Sraffa no aborda los sujetos sociales a los que se destina el excedente ni las relaciones sociales establecidas entre ellos, y no porque "ese trabajo estaba hecho", como dice Mora Plaza, sino porque no entra en el horizonte de su lógica y de su teoría. "Para qué repetirse" afirma Mora Plaza, pero es que aceptar esto ¿no sería enfrentarse con el análisis de Marx en torno de tales relaciones reales, o sea del antagonismo de clase? $Y$ esto es precisamente lo que Sraffa repugna en Marx.

$3^{\circ}$ ) "El modelo de Sraffa estudia el conjunto de todas las empresas y de los bienes y servicios en su mutua interdependencia... En el modelo de Sraffa la interdependencia es fundamental para establecer relaciones entre las variables monetarias del sistema: precios, ganancias y salarios..."

Congruente con su lógica que exige la "descontaminación" ("depuración") de los conceptos de su fuente real en las relaciones sociales entre las clases, no podía ser sino que la "mutua interdependencia" no se tratara de aquellas relaciones sino de las "variables monetarias". Las cosas (empresas, bienes, servicios) se mueven por sí mismas, tienen vida propia, muestran iniciativas, etc. y toman la forma de "variables". Esto es en verdad fetichismo, animismo, no ciencia como creen los sraffianos tan antimetafísicos como se muestran. Además es necesario recordar que la economía vulgar al estilo J-B-Say y la de 
la escuela neoclásica también tienen en cuenta las "acciones recíprocas" de los fenómenos económicos, no será aquí esto una especial diferencia entre Sraffa y el marginalismo sino más bien una similitud.

$\left.4^{\circ}\right)$ Los precios. Sraffa, según Mora Plaza, parte de reconocer lo que “... hacen todos los comerciantes y empresarios del mundo: añadir un margen a los costos para obtener los precios de venta". A. Roncaglia, dice que "Los precios de producción estudiados por él (Sraffa) son sencillamente aquellos que, para niveles dados de actividad, corresponden a un tipo de beneficio uniforme en todas las industrias... es un tipo de beneficio contable..." (A. Roncaglia, "Sraffa y la teoría de los precios", Pirámide, Madrid, 1980, p. 14). Esta es otra modalidad de determinación de los precios diferente del de Marx basado en un cálculo en términos de valor de $\mathrm{c}+\mathrm{v}+\mathrm{g}$, siendo $\mathrm{g}$ la tasa de ganancia uniforme, pero no parece constituir una "teoría de los precios" ya que según Mora Plaza lo que hace Sraffa es partir de lo que hacen los comerciantes y empresarios de todo el mundo, o sea, parte de un hecho práctico no lo explica.

$\left.6^{\circ}\right)$ El Capital. "Para Sraffa el capital es solo trabajo fechado". "El capital, es decir, el conjunto de los medios de producción que alguna vez han sido producidos, lo ha sido por obra de la mano del hombre. Ningún extraterrestre ha hecho el trabajo por nosotros, nadie nos lo ha regalado. Es algo tan de sentido común que cuesta explicar lo evidente". "El capital es sólo trabajo fechado, un mero instrumento de trabajo que ya incorporó a su vez trabajo en su producción en el pasado"

De modo que el capital es concebido: $1^{\circ}$ ) como trabajo acumulado (trabajo que ya incorporó a su vez trabajo en su producción en el pasado); $2^{\circ}$ ) como cosa no como relación (un mero instrumento de trabajo)

19) Trabajo acumulado: "Cuando se dice que el capital "es trabajo acumulado (realizado)" -hablando con propiedad trabajo objetivado - que sirve de medio al nuevo trabajo (producción), se toma en cuenta la simple materia del capital y se prescinde de la determinación formal, sin la cual no es capital. Equivale a decir que el capital no es sino instrumento de producción, pues en el más amplio sentido, antes de que un objeto pueda servir de instrumento, de medio de producción, es necesario apropiárselo mediante una actividad cualquiera, aunque sea un objeto suministrado íntegramente por la naturaleza, como por ejemplo las piedras. Según lo cual, el capital habría existido en todas las formas de la sociedad, lo que cabalmente es a-histórico. Conforme a esta tesis cada miembro del cuerpo sería capital, ya que debe ser no sólo desarrollado sino también nutrido y reproducido por la actividad, por el trabajo, para poder ser eficaz como órgano. El brazo, sobre todo la mano, serían capital, pues. El capital sería un nuevo nombre para una cosa tan vieja como el género humano, ya que todo tipo de trabajo, incluso el menos desarrollado, la caza, la pesca, etc., presupone que se utilice el producto del trabajo precedente como medio para el trabajo vivo e inmediato. Otra determinación de la definición citada más arriba es que se abstrae totalmente la sustancia material de los productos y se considera al trabajo pasado como su único contenido (sustancia). De igual modo se hace abstracción del objetivo determinado, específico, para cuya 
formación este producto debe servir ahora nuevamente como medio, y en calidad de objetivo se establece tan sólo una producción en general. Todo esto aparenta ser únicamente la obra de la abstracción, que es igual en todas las condiciones sociales y que sólo lleva más adelante el análisis y lo formula de manera más abstracta (más general) de lo que hasta entonces solía ocurrir.

20) Capital como cosa: "Si de este modo se hace abstracción de la forma determinada del capital y sólo se pone el énfasis en el contenido, que como tal es un momento necesario de todo trabajo, nada más fácil, naturalmente, que demostrar que el capital es una condición necesaria de toda producción humana" (énfasis de Marx). Se aporta la prueba correspondiente mediante la abstracción de las determinaciones específicas que hacen del capital el elemento de una etapa histórica, particularmente desarrollada, de la producción humana. El quid de la cuestión reside en que, si bien todo capital es trabajo objetivado que sirve como medio para una nueva producción, no todo trabajo objetivado que sirve como medio para una nueva producción, es capital. El capital es concebido como cosa, no como relación. (énfasis de Marx)... El capital no es una relación simple, sino un proceso, en cuyos diversos momentos nunca deja de ser capital"

De manera que "Cuando se dice que el capital es "trabajo acumulado" que sirve de medio al nuevo trabajo (trabajo fechado de Sraffa) se toma en cuenta la simple materia del capital y se prescinde de la determinación formal, sin la cual no es capital. Equivale a decir que el capital no es sino instrumento de producción, pues en el más amplio sentido, antes de que un objeto pueda servir de instrumento, de medio de producción, es necesario apropiárselo mediante una actividad cualquiera, aunque sea un objeto suministrado íntegramente por la naturaleza, como por ejemplo las piedras. Según lo cual, el capital habría existido en todas las formas de la sociedad, lo que es cabalmente ahistórico" (Cfr. Marx Grundrisse, I, pp. 196-198)

¿Qué es esto? Pues la consecuencia de la hipostatización (sustantivación) de las abstracciones a partir de lo inmediato (forma de aparición). ¡Qué cosa tan de sentido común y tan evidente al punto de que cuesta explicarlo! El capital como trabajo es algo de todas las sociedades y todos los tiempos porque "ningún extraterrestre ha hecho el trabajo por nosotros" por eso se puede reducir todo a "trabajo fechado" ¿qué tipo de trabajo? ¿en qué específicas relaciones de producción? ¿hasta qué época retroceder con la datación? Nada se dice al respecto ¡he aquí un resultado de la "depuración" de los conceptos de su base social e histórica! Por supuesto que finalmente en toda sociedad hubo que trabajar: de este modo se pierde la especificidad. ¿Por qué? Porque el concebir la economía teórica como un sistema matemático exige "despojarse" inevitablemente de las propiedades sociales e históricas de las cuales surgen, para resolver sólo las ecuaciones bajo las que se presenta el modelo. Esto es pensar la economía desde la matemática, no usar ésta para exponer conceptos económicos con rigurosidad, es una consecuencia inevitable del trastrueque de objeto y método.

Compárese esta "evidencia de sentido común" con otra advertencia de Marx (Grundrisse cit., I, p. 273): Es necesario desarrollar con exactitud el concepto 
de capital, ya que el mismo es el concepto básico de la economía moderna, tal como el capital mismo -cuya contrafigura abstracta es su concepto- es la base de la sociedad burguesa. De la concepción certera del supuesto fundamental de la relación, tienen que derivar todas las contradicciones de la producción burguesa, así como el límite ante el cual ella misma tiende a superarse".

Y agreguemos aún: "La concepción del capital que atiende únicamente a su aspecto material, a su calidad de instrumento de producción, prescindiendo totalmente de la forma económica que convierte al instrumento de producción en capital, hace que los economistas se extravíen en dificultades de toda índole... Aquí, pues, el capital coincide totalmente con el instrumento de producción en sentido tecnológico, conforme a lo cual cualquier salvaje es un capitalista" (Grundrisse, II, p. 93). Eliminada la forma social de producción por la cual un instrumento, una herramienta, una máquina, es capital ¿qué queda? Pues queda el ser un mero instrumento, una mera herramienta y una mera máquina: ¡son cosas! ¿por qué, pues, no se los denomina directamente e inmediatamente "herramientas", "instrumentos", "máquinas", etc.? o ¿por qué no se dice de cada uno de ellos "son sólo trabajo fechado"? Pues porque son en verdad "capital", o mejor dicho, cada una de esas cosas dejan de ser tales en lo inmediato para mutar en "capital" como resultado del producto del trabajo bajo una forma social específica de producción dominada por la clase empresarial en la que el trabajo es asalariado y no esclavo o servil. Como se ve estamos ante una metafísica positivista vulgar e ingenua de la economía, pero A. Mora Plaza parece no tener idea de esto porque él no se detiene ante minucias metafísicas, sociológicas y/o institucionales. (?)

$7^{\circ}$ ) Sraffa no tiene ninguna teoría sobre la determinación de la distribución entre w y g. Afirma Mora Plaza que sin embargo “... es fácilmente deducible por omisión: la lucha de clases. Por supuesto que el italiano no menciona esa expresión en toda su obra ni nada que lleve a ella, pero permanece implícita".

¡Esto no puede ser aceptado! Sencillamente porque ¡no es cierto que tal "hecho social real" esté implícito! Va contra toda la lógica de la obra y pensamiento de Sraffa. De la misma manera puedo afirmar que lo implícito es: "la colaboración y armonía" de las clases en torno de la distribución en pro del "bien común" y esto no alteraría para nada el análisis de Sraffa sobre el tema dado que las clases involucradas se enfrentarían en discusiones y situaciones que no anularía la diferencia de intereses pero que estarían sí absorbidas por la finalidad "solidaria" que exige el reparto del plusproducto. También es posible que intervenga (icomo interviene!) el Estado estableciendo la distribución por decreto o por ley: el excedente siempre se distribuirá en diferentes magnitudes proporcionales sea por lucha sea por acuerdos sea por imposición estatal.

Pero aun más, aceptando que el w y la g constituyen fracciones o magnitudes del excedente como Sraffa lo presenta, la lectura apropiada que se desprende de tal posición es la eliminación del carácter específico de la relación capitalista de producción, esto es, la compra de Ft (trabajo vivo) por el $K$ como una inversión variable por parte del patrimonio dinerario de la clase capitalista, queda oculto por tanto el hecho que la clase trabajadora está excluida de la propiedad del producto y tenga por tanto que re-adquirir 
constantemente una parte de su propio producto a cambio de su trabajo vivo para el capital. De esta manera, la clase trabajadora puede ser concebida actuando cual si fuera empresaria y que como tal le correspondiera una parte del excedente por ser propietaria copartícipe en la apropiación del plusproducto. En lugar de clase explotada se la equipararía de este modo a clase explotadora como la capitalista. Se tendría de esta manera un capital como fetiche y como cómplice un trabajo también fetiche. (Cfr. K. Marx, "El Capital", Siglo XXI, Bs. As. 1975, Libro I, vol. II, cap. XVI, p. 648).

A. Mora Plaza podrá argumentar que esta explicación es "forzada" ya que nada hay en Sraffa en tal sentido. Y sería cierto, pero es tan forzada como aquella que da "por implícito" en él la "lucha de clases". No obstante subrayaremos que la lectura que hacemos no nace de un capricho personal sino de lo que ha elaborado Sraffa al poner por "razones matemáticas" al trabajador en el mismo nivel que el capitalista aprovechando ambos el excedente y aún podrá Plaza señalar que incluso en este caso no habría que excluir el "conflicto" por el reparto que es lo que interesa: pero no es así, la lucha de clases entre trabajadores y capitalistas es mucho más que "esperables disensos" entre capitalistas por repartirse en diferentes proporciones lo que otros han creado.

Es posible advertir entonces que la fijación de w y g seguirá siendo exógena pero no es lo mismo una u otra causal en los hechos reales de la oposición trabajadores/capitalistas. Los sraffianos que adoptan esta posición sobre el tema no son pocos y consideran que esto los acerca y valoran a Marx; de ninguna manera es cierto esto. "Intuyen", "huelen" que el matematismo de Sraffa y la modalidad ecuacional de pensar y presentar su modelo los ha llevado a una estratósfera analítica y entonces pretenden volver a lo real y ahora sí "poner los sujetos" desde afuera y cuando las formulas se lo permiten iporque el modelo tiene aquí un grado de "libertad sobrecogedora"!. De modo que a lo real le es permitido "entrar" en el modelo para validarlo (isic!) porque así guardaría relevancia empírica. A. Mora Plaza, precavido él, afirma al respecto que si la distribución fuera de carácter endógeno el modelo no sería "sraffiano". ¿Sería obra de "extraterrestres"?

$\mathbf{8}^{\circ}$ ) Es claro que en Sraffa no hay nada de eso que conciben los marginalistas de tomar decisiones para maximizar funciones. Al no haber empresarios, ni trabajadores, ni empresas, ni sindicatos, i.e. nada de "sujetos sociales" no puede haber ni maximización ni minimización. ¿Quiénes son los protagonistas? , pues "las mercancías (hoy bienes y servicios) los sectores y los procesos, y no las empresas y los consumidores" (aquí las palmas se las llevaría el marginalismo, porque aunque mal, al menos pretende guardar una referencia a la realidad). ¿Qué es el capitalismo? "el conjunto de las relaciones intersectoriales de la economía". "Y a los efectos económicos, para lo que llamamos economía, lo importante es lo que se produce y cómo se distribuye..." La cuestión en realidad es ¿Quiénes producen y cómo producen? No ¿qué se produce y cómo se distribuye? De manera que si preguntamos ¿cómo se crea lo que luego tendrá que ser distribuido?, precisamente sólo la naturaleza específica de la relación entre trabajadores asalariados y capitalistas, o la differentia specifica del capital, es la que explica este proceso en el momento de producción y no de su distribución. 
En el análisis de Marx están los protagonistas centrales de la sociedad actual: capitalistas y trabajadores, es en ellos y su antagonismo que descansa la fuente de los conflictos y el origen de los conceptos, éstos expresan teóricamente situaciones de lo real. ¿Qué todo puede ser llevado a un modelo sencillo y preciso de carácter matemático? ¡Qué duda cabe! El problema no es la simplificación matemática. El problema es ¿qué se está estudiando y que leyes rigen el objeto real estudiado?

$\left.9^{\circ}\right)$ Remate notable de la nota y de Sraffa: "En Sraffa se echa de menos una teoría -una explicación- de la producción, del mercado y de la asignación de recursos". (?) Pero no sólo falta esto. No hay en Sraffa, él no se lo propuso sea dicho en verdad, teoría del ciclo, teoría de la inversión, teoría de la desocupación, teoría del interés, teoría de la acumulación de capital, etc. Demasiados temas y teorías faltan en Sraffa, pero no sería justo achacarle tales faltantes; importa lo que realizó y sobre ello vale su estudio y la crítica.

El gran discípulo de Sraffa, Luigi Ludovico Pasinetti, dice que "Falta completamente en Producción... cualquier referencia a un tipo de agente económico, falta más bien el propio agente económico; faltan las preferencias del consumidor; faltan hipótesis sobre el comportamiento del empresario y su elección de tecnología ante variaciones del nivel de actividad (tampoco se hacen hipótesis sobre sus rendimientos de escala). Sraffa no habla de concurrencia, no se refiere a empresas ni habla tampoco de Estado. Nada dice sobre modelos de comportamiento ni de órdenes institucionales. Hasta el tema de la distribución del ingreso, tan central en PMM, queda abierto a múltiples soluciones alternativas" (L.L. Pasinetti, "Sraffa e la matematica: diffidenza e necessitá. ¿Quali sviluppi per il futuro?; Accademia Nazionale del Lincei, 11-12 febrero 2003)

La finalidad de construir una nueva teoría económica sobre los fundamentos puestos por Sraffa en "Producción..." hace a un lado el inmenso trabajo de Marx como si lo hecho por éste fuese descartable por inútil o lo que pudiere quedar en pie de su obra sea fácilmente integrable al superior pensamiento de aquél (y de ser esto así no se ve por ningún lado la obra de economista sraffiano alguno, o un conjunto, que haya acometido tal tarea), y además, descansa en la convicción de que la Economía Política con Sraffa ha alcanzado el status de ciencia estricta cual ciencia natural, y que como sostiene Mora Plaza hay que desarrollarla, actitud completamente errada. ¿Nueva teoría económica sobre viejos y vulgares fundamentos? Ahora bien, de lo que A.M. Plaza nada dice es de las coincidencias del análisis de Sraffa con el marginalismo. No es ésta una tarea inútil porque tales coincidencias existen.

Fernando Hugo Azcurra

Diciembre 2011 


\section{Sraffa y la teoría del excedente. Respuesta a fernando azcurra, i parte}

\section{Antonio Mora Plaza}

Me creo en la obligación de dar una contestación a Fernando Hugo Azcurra a su artículo Sraffa y la metafísica de la economía por dos motivos al menos: 1) porque es este un artículo solvente, que denota un buen conocimiento de la obra de Marx, a partir de la cual hace una crítica a mi artículo referido a lo que yo creo que debiera ser el cañamazo de una nueva teoría económica partiendo de la obra de Piero Sraffa, Producción de mercancías por medio de mercancías; 2) porque su solvencia es notablemente mayor cuando aborda punto por punto lo publicado por mí que cuando se analiza la visión global del mismo. Yo empezaré por esto último, por esta visión global en mi opinión errada de Fernando, pero antes querría decir que ambos -creo yo- estamos en el lado de la heterodoxia, de la crítica al modelo estándar de la teoría económica actual, que es el marginalismo y de la crítica al keynesianismo adulterado imperante. Digo esto último porque lo que se estudia en los manuales de macroeconomía de supuesto keynesianismo no se corresponde con lo que dijo Keynes, sino que es una interpretación posterior (Hicks), que es el modelo de equilibrio IS-LM. Esto ya lo dejó claro Pasinetti en su obra Crecimiento económico y distribución de la renta, pero lo que triunfado en los manuales es la teoría de la síntesis de Samuelson. Y eso en el mejor de los casos. Pero antes de seguir sólo un inciso imprescindible, porque de no hacerlo parecería a cualquier lector no avezado en la historia del análisis económico y sus avatares que la obra de Piero Sraffa se explica en las facultades de economía al menos en pie de igualdad que la micro marginalista, la adulterada keynesiana, las teorías del crecimiento o la teoría de los juegos, por poner cuatro ejemplos. Nada más lejos de la realidad, porque Sraffa no sólo no se estudia, sino que desde el mismo momento de la publicación de su obra capital -omito los dos importantísimos artículos de 1925 y 1926-, ésta ha sido ocultada, arrinconada, convertida en una acnédota y no forma parte del corpus intelectual de la formación de un economista. Algo menos en Italia, que por ser el autor italiano -turinés para más señas-, tiene algo más predicamento y se han hecho congresos y publicaciones en el 2010 con motivo del 50 aniversario de la publicación de su obra (Sraffa or an alternative economics, 2008). Estudiosos de Sraffa, aunque no necesariamente esrafianos, son Garegnani fallecido muy recientemente-, Pasinetti, Kurz, Schefold, Roncaglia, Steedman, Salvadori, y un largo ecétera de, fundamentalmente, economistas italianos. También he encontrado en Latinoamérica estudiosos de la obra y quiero mencionar especialmente el grupo Circus-Luján en Argentina, al que pertenece Fernando. En España, casi el desierto, con la excepción de Manuel Ahijado que en su día -en 1982- escribió un libro importante, aunque pasara desapercibido en el mundillo económico como fue Distribución, precios de producción y crecimiento. Antes de la obra de Ahijado -en 1979- escribía Josep M. Vegara Economía política y modelos multisectoriales, donde dedicaba a la obra de Sraffa un capítulo. Yo la primera vez que oí hablar de Sraffa fue al profesor Lozano -del que no he vuelto a saber nada-, y aquello 
ocurrió cuando ya estaba acabando la carrera, hace ya más de 30 años. El por qué de este ocultamiento es fácil de comprender al leer el libro de Sraffa, porque éste no es sólo una crítica a la teoría del capital neoclásico, sino que va más allá y supone la más acertada teoría del excedente, que es el núcleo duro de la preocupación de los clásicos, al menos desde David Ricardo hasta Alfred Marshall. $Y$ esto suponía ir contra corriente, contra la corriente neoclásicamarginalista imperante, cuya fuente de preocupación es las supuestas asignaciones, la búsqueda de imposibles equilibrios generales o la formación determinística de los precios. Diría que la obra de Sraffa -aunque no su gestación, es decir, su filogénesis- trata de resolver el problema de Ricardo de encontrar una medida invariante de la distribución y de los precios -cosa que consigue Sraffa con la mercancía-patrón y la razón-patrón-, y sigue con o contra la teoría del capital y su creencia de que puede generalizarse una teoría que ponga en relación inversa y monótona la relación capital/trabajo y el tipo de interés; también que se pueda hablar de capital como un agregado, al igual que se hace con el trabajo y se hacía con la tierra. Esta teoría ya había sido vapuleada por Robinson, Garegnani, Pasinetti, Nuti, Badhuri, etc., pero como la hidra de siete cabezas o un ave Fénix de mal agüero, les sale nuevas cabezas o renace de sus cenizas. Aún está increíblemente esta visión errónea en los manuales de microeconomía que estudian los que luego toman decisiones en el FMI, en el Banco Mundial, en la Reserva Federal, en el Banco Central Europeo, etc. Sé de sobra que Fernando sabe todo esto y mucho más, pero lo cuento para el lector menos avezado, pero que padezca del sarpullido de la... curiosidad.

Entraré ahora en la crítica de Fernando. Acabado el artículo yo tengo la impresión de que el autor considera de partida que la obra de Sraffa y Marx son sustitutivas, lo cual me sorprende porque doy por supuesto que ha leído con detenimiento la obra de Sraffa y es seguro -porque lo demuestra- que tiene un conocimiento profundo de la de Marx. Por ejemplo, Sraffa estudia el excedente y llega a establecer una relación variable entre salarios y ganancias -tasas, pero pueden generalizarse sin dificultad-independiente 0 , mejor dicho, dado el trabajo con todas sus características, los medios de producción con su heterogeneidad y los productos finales, sean cuales sean estos. Esta forma de proceder de Sraffa hay que entenderlo como la manera que tiene el economista italiano de refutar la economía marginalista, donde salarios y ganancias son derivadas de supuestas productividades marginales, productividades que para serlo ha de suponerse una teoría de la producción y del capital previa. Pero esto ya hemos visto que ha sido refutado por dos motivos: por inconsistente y irrelevante, es decir, por su nula relación con la realidad. Sraffa trata de refutar a Marshall, Walras, a los austríacos, pero no a Marx. Nada dice Sraffa de las relaciones de producción que se dan en ese reparto entre salarios y ganancias. Ahí te cabe Fernando la teoría de la explotación de Marx, que es el núcleo duro de su teoría económica, aunque sabemos que Marx es más que un mero economista y su análisis económico va mucho más allá que la teoría de la explotación. Más aún, si lees mi libro -y perdona por citarme- Descifrando a Sraffa verás que llego a establecer una relación meridiana entre la razón-patrón de Sraffa y la composición orgánica de capital de Marx. Esta crítica de Sraffa por lo que no tiene me parece injusta, porque con esa cualquier autor u obra saldría negativa su valoración, incluido la del propio Marx. En mi opinión una 
obra que pretende ser científica -y ya es esto difícil en el campo de lo socialpuede ser criticada por estas tres cosas: 1) por su incoherencia, si es que se da; 2) por su escasa o nula capacidad predictiva; 3) por su posible irrelevancia. Creo que hay que atenerse a estas tres cosas. En todo caso soy yo el que arriesga al considerar que Sraffa -su obra concreta de Producción de...puede ser considerada como la semilla de unos nuevos fundamentos de una nueve teoría económica. Es decir, no se trata de inventar una enteramente nueva teoría económica, sino de fundamentar esa nueva teoría a partir de Sraffa, pero con las aportaciones de, por ejemplo, Ricardo (teoría de los costes comparativos, teoría de la renta de la tierra), Keynes (demanda efectiva, teoría monetaria), Kalecki (dinámica económica), Marx (teoría de las crisis, teoría de la explotación, teoría de la reproducción y acumulación), etc. Son sólo algunos ejemplos, nada de una enumeración exhaustiva, y que admito que podrían ser contradictorios entre ellos. Sraffa aportaría el basamento de todo ello a partir del excedente, la producción conjunta, el capital como trabajo fechado, el capital fijo. No son todas las aportaciones de Sraffa, pero son las que me parecen más importantes.

Cuando digo que Sraffa parte de toda la realidad creo que lo explico, pero lo matizo si es necesario. La realidad como tal sabemos que es inasible, eso lo damos por descontado y no ha sido necesario que Kant distinguiera entre el fenómeno y el noúmeno para saberlo. Lo que digo son dos cosas: 1) Sraffa parte de la misma realidad de la que parte Leontief con sus tablas Input-Ouput, tablas que son unos de los mejores instrumentos -para mí el mejor- para el estudio de los fenómenos económicos en forma de inevitables agregados. Esto debiera ser obvio porque, por más compleja que sea una tabla de datos, incluso las más complejas, como fueron las de la planificación soviética, es imposible meter en una tabla los cientos o miles de millones de productos diferentes que se producen en un año con sus precios respectivos. Esa realidad es siempre un agregado de cosas que tienen un cierto grado de homogeneidad. Y no se ha inventado nada más cercano a la realidad que una tabla de Leontief, ni existe instrumento mejor para indagar con posibles variaciones de, por ejemplo, inversión, ahorro, trabajo, producción, precios, etc. Pues bien, la matriz de datos que emplea Sraffa -aunque Sraffa no emplea ese lenguaje- es el mismo que el que emplea Leontief. A eso me refiero con realismo; 2) Porque esa realidad viene, a pesar de lo anterior, desagregada por bienes y sectores (o procesos), en sus relaciones interdependientes, intersectoriales, a diferencia de los modelos productivistas marginalistas (modelo Cobb-Douglas, por ejemplo, el CES, modelos de crecimiento, etc.). En Sraffa, a diferencia de los modelos marginalistas agregados, es fundamental el análisis de las diferentes composiciones llamemos capital/trabajo de los sectores que influyen directa y/o indirectamente en la formación de los precios. Nada de esto es incompatible con Marx, sino todo lo contrario, porque Marx estudia, aunque simplificadamente, los diferentes sectores y su reparto. Es verdad que siempre desde su papel en la formación de la plusvalía y su reparto, y en su papel en la reproducción y acumulación del sistema. Esta última, su teoría de la reproducción y acumulación es perfectamente compatible con la teoría del excedente de Sraffa con tal de fechar los precios en el modelo de éste. Lo tienes en el libro que te he mencionado. Es verdad que también hay que casar conceptos, pero eso ha de ser tarea de los demás y no podemos 
criticar a Sraffa porque no lo hiciera. Tú mismo lo señalas, por lo que estamos de acuerdo en este punto.

Dices que considero que con Sraffa la economía ha alcanzado un status de "ciencia estricta cual ciencia natural". No recuerdo haber dicho eso pero, en todo caso, me explico. Considero precisamente que con Sraffa, dados los huecos de su explicación de lo que puede ser entendido como fenómenos económicos, queda desechada la posible creación de una ciencia social en pie de igualdad con las ciencias naturales. $Y$ eso se debe precisamente a las ausencias que tú mismo criticas en Sraffa. En mi opinión podemos definir la economía de Sraffa como el estudio -no ciencia- del excedente y de sus límites. Ni más ni menos. Ni siquiera nos habla del reparto, ni de la relaciones sociales de la manera que nos habla Marx, autor que sí creía haber creado o descubierto -es verdad que quizá lo creyó más firmemente Engels en el AntiDühring y en Del socialismo utópico al socialismo científico- una ciencia de lo social con el mismo status que las ciencias físicas conocidas entonces. Tal es así que si no se quiere que la obra de Sraffa caiga en la trivialidad de una mera teoría del todo -que es su punto débil- debemos completarla y complementarla. Ahora bien, de aceptar la imposibilidad de una ciencia de lo social -al menos en el subconjunto de lo que pueda entenderse como conocimiento de los fenómenos económicos- con el mismo status de universalidad y necesidad que las ciencias físicas, eso no nos debe llevar a la otra orilla, a la orilla robinsoniana de la economía como una mera "caja de herramientas". Y eso, en mi opinión, lo que representa Sraffa en lo que atañe a los fundamentos y sólo a los fundamentos.

En lo concerniente al capital como trabajo fechado de Sraffa no entiendo tu crítica a Sraffa. Lo que haces, Fernando, es criticar al italiano porque no dice lo que dice Marx del trabajo. Eso es cierto porque Sraffa no copia a Marx y tampoco parte de él. No entra en consideraciones como hace Marx -por ejemplo- en el capítulo VI del II tomo de El Capital donde dice que "el obrero añade al objeto sobre el que recae el trabajo nuevo valor incorporándole una determinada cantidad de trabajo, cualesquiera que el contenido concreto, el fin y el carácter técnico de este trabajo sean". Son las consideraciones de Marx sobre el trabajo abstracto y concreto. La cuestión es: ¿Acaso es falso o descabellado considerar que el capital, es decir, los medios de producción, es trabajo del pasado? ¿Es relevante en el modelo de Sraffa esta consideración? ¿Acaso es contradictorio con la concepción de Marx? Es sobre todo una critica demoledora a la teoría del capital neoclásica, no a la teoría del capital de Marx. Nada de lo que dices o de lo que dice Marx es incompatible con lo que dice Sraffa. Por ello no entiendo tu crítica. Sraffa no es Pierre Menard, ese personaje de Borges que vuelve a escribir El Quijote línea a línea, palabra por palabra. Sraffa no reescribe El Capital. Eso no puede ser un defecto del italiano; menos aún si, como yo considero, no es sustitutivo en este punto sino complementario. Cosa distinta sería si, como hace Morhisima -por poner un ejemplo- basara la teoría de la explotación de Marx en la mera prolongación de la jornada de trabajo (Marx's Economics, 1973). Dice Marx también en El Capital (cap. V, sección III, libro II) que "los productos existentes no son solamente resultados del proceso de trabajo, sino también condiciones de existencia de éste; además, su incorporación al proceso de trabajo, es decir, su 
contacto con el trabajo vivo es el único medio de conservar y realizar como valores de uso estos productos de un trabajo anterior". Se pueden citar decenas de textos de Marx como este donde no entiendo que pueda ser incompatible la concepción del capital de Marx con el cálculo y consideración las dos cosas, concepto y aritmética- de Sraffa del capital existente en cada momento como suma ponderada de los medios de producción utilizados en el pasado. Llegado al extremo, podemos considerar que Sraffa toma como un dato el trabajo implicado en la producción, sin más consideraciones. Puede ser una oquedad, uno de las cosas que no están presentes en Sraffa, pero estas ausencias es lo que sitúa a Sraffa -en mi opinión- como el mejor candidato para fundamentar una nueva teoría económica: por la porosidad de su obra y la orfandad en temas importantes. En un segundo artículo publicado por mí también en Nueva Tribuna que no comentas, señalo las tres características que debiera tener un modelo para ser tildado de esrafiano: el grado de libertad entre salarios y ganancias, la formación de los precios mediante un margen sobre los costos y el capital como trabajo fechado. Son, en mi opinión, las tres patas de estos fundamentos, y ahí caben buena parte del análisis posterior a Ricardo, incluido Keynes, Kalecki y Marx, porque Sraffa, a diferencia del alemán que crea un modelo autónomo y globalizador, no pretende crear una teoría del todo, sino cosas mucho más limitadas: 1) atacar la teoría del capital neoclásica en su capítulo sobre los desplazamientos de los métodos de producción; 2) resolver el problema de Ricardo de una medida invariante de los precios y la distribución; 3) atajar la simplificación de la economía neoclásica sobre la producción simple; 4) incorporar el capital fijo porque considera que no esté bien resuelto por Ricardo; 5) señalar la importancia de la diferenciación entre bienes básicos y no básicos, es decir, los que entran como medio y los que no, para la formación de los precios. No es todo Sraffa, pero es una parte sustancial. No lo juzgo por sus intenciones -que también puede hacerse- sino por sus resultados. No pretende mucho más; desde luego mucho menos que Marx, pero son dos economistas distintos, geniales, que escriben casi con un siglo de diferencia. Sraffa es una montaña sobresaliente, quizá la más alta; Marx es una cordillera, quizá la más larga. La fortuna para nosotros, los simples mortales, es que son, en mi opinión, compatibles en un alto porcentaje.

Donde podemos encontrar dificultades de encaje entre ambos economistas es en su teoría de formación de los precios. Marx parte de su teoría del valor y tiene que hacer la transformación a precios; en Sraffa, como dice Roncaglia, son precios correspondientes a tasas únicas de salario y ganancia (y a largo plazo). Sraffa los llama precios de producción. Yo aquí tengo una profunda discrepancia tanto con el propio Sraffa como con Roncaglia. Con Sraffa porque malamente se le pude llamar precios de producción a unos precios surgidos de un modelo huérfano de una teoría de la producción y de una teoría de los costes. En mi opinión añadiría que... afortunadamente. Los precios de Sraffa son de intercambio y de reproducción del sistema. Son precios de equilibrio, mal que nos pese. Si se tiene duda no hay más que ver que el vector de precios de los productos finales que emplea Sraffa es el mismo que el de medios de producción. A diferencia de la teoría del equilibrio general que busca alcanzar unos precios -un vector de precios- único y estables, Sraffa parte de unos precios de equilibrio dado que el vector de precios que define su modelo es el mismo tanto para los medios de producción como para los productos. No 
es que Sraffa busque un equilibrio porque para nada le interesa semejante tontería, pero parte de él. Al fin y al cabo la razón-patrón se construye a partir del teorema de Perron-Frobenius, que es un teorema del punto fijo. Además, los salarios son post-factum, es decir, que no incluyen los costes salariales para su formación. Todo esto es subsanable, fechando precios y englobando salarios en los costes. Yendo a Marx, Samuelson habló de los precios de Marx como de un rodeo innecesario. Pero el dilema en la teoría de Marx está servido: o transformación o renuncia a la teoría del valor trabajo; incluso renuncia a la teoría de la explotación, con lo cual nos quedamos sin Marx. La cuestión es si son compatibles la teoría de la explotación (generadora de la plusvalía) con los precios de Sraffa. No tengo respuesta, al menos de momento. En cualquier caso conjeturo que fue la teoría del valor-trabajo ${ }^{11}$ lo que llevó a Sraffa a apartarse del modelo de Marx, aunque siempre fue marxista de corazón. Es verdad que para lo que nos ocupa, eso no vale para nada, pero puede ayudar a comprender el doble abismo por el que se mueve Sraffa: por un lado ataca la teoría del capital y el marginalismo, pero por otro su no aceptación del modelo marxiano -y en especial, creo yo, la teoría de los precios del alemán- le fuerzan a crear un nuevo modelo a partir de Ricardo. Pero para estar seguro de todo esto debemos esperar a conocer toda la correspondencia de Sraffa que ahora se da a conocer y que Kurz y Garegnani son -era en el caso del italiano- los albaceas intelectuales del turinés.

En cualquier caso tampoco entiendo la crítica que haces cuando digo que los precios se forman a partir de un margen sobre los costos, cosa que hace cualquier comerciante (o empresario) y dices que parto de un hecho práctico, pero que no lo explico. ¿Cómo puede ser un defecto construir un modelo -que no deja de serlo- basado en comportamientos cercanos a la realidad? Es precisamente uno de los puntos fuertes del modelo de Sraffa frente a la explicación marginalista de que los precios se forman al igualar supuestos ingresos marginales con costes marginales. Es verdad que yo soy partidario de incluir los salarios en los costes para formar estos precios precisamente porque eso añade realismo, pero tú en este aspecto no entras por lo que yo no lo haré. Yo añadiría algo más: que la economía o es una sociología o son meras fórmulas y gráficos. $Y$ este comportamiento empresarial es uno más que explica en parte la formación de los precios en el mismo plano de igualdad que en el keynesianismo explica el consumo a partir de la propensión al consumo, el marginalismo la demanda a partir de la utilidad marginal o cuando Marx trata la plusvalía como "la diferencia entre el trabajo considerado como fuente de valor de uso y el mismo trabajo en cuanto que crea valor"12. Podrán o podremos considerar explicaciones acertadas o no, pero son explicaciones. Todo el libro de Sraffa es un continuo intento de construir un modelo basado en explicaciones sobre comportamientos económicos. También en el tema de la formación de los precios. Tal es así que una de las mayores dificultades del libro es precisamente seguir el rastro de esos comportamientos al partir de la economía como un todo, con sus relaciones intersectoriales, con sus relaciones entre trabajo y medios de producción, entre variables monetarias (precios,

\footnotetext{
${ }^{11}$ Sraffa after Marx: An open issue, Riccardo Bellofiore, (dentro de Sraffa or an alternative economics, 2008).

${ }^{12}$ El Capital, I tomo, sección III , cap. V, Proceso de trabajo y proceso de valoración, pág. 147, FCE, 1974..
} 
salarios y ganancias) y variables no monetarias (medios de producción, trabajo y productos finales). Si esto no se aprecia sólo se aprecia en Sraffa un mero sistema de ecuaciones. Sraffa no es Leontief. El economista ruso nacionalizado norteamericano crea un precioso instrumento para extraer consecuencias de la realidad, pero sin teoría. Leontief no tiene una teoría: esa la tenemos que poner los demás. Pero Sraffa sí la tiene. La construye a partir del excedente y sigue con la producción simple, conjunta, la reducción del capital a trabajo fechado, el desplazamiento de los métodos de producción, con el capital fijo y las mercancías que se auto-reproducen (apéndice B del libro de Producción de... ). A partir de Sraffa podemos estudiar la producción conjunta, la renta de la tierra, el capital fijo, el comercio internacional, el mercado de trabajo, la reproducción y acumulación, el crecimiento, el cambio de las técnicas, etc. Y usa además instrumentos como la mercancía-patrón y la razón-patrón y cosas como la diferenciación entre productos básicos y no básicos, que son a la vez objeto e instrumento. Si no se entiende que Sraffa basa su obra en comportamientos no se entiende a Sraffa. No digo que por eso se haya que estar de acuerdo con él, digo que no se entiende su libro. Sraffa no es Leontief y menos aún Von Neumann, con su modelo que tantos puntos de conexión tiene con el italiano en los aspectos formales (matemáticos). Creo que ya lo he dicho, pero insisto: que Sraffa no explica todas las cosas a pesar de que parta de la realidad como un todo. Por eso hablo de fundamentos y no de una teoría o modelo acabado como podemos considerar que es el marxismo o el marginalismo. Ambos son modelos cerrados, donde parece imposible meter la cuchara de la creación: 0 se aceptan o no se aceptan. Reconozco que no me gusta esa especie de catecismo que ambos representan. $Y$ desde luego si los precios de Sraffa te pueden parecer Fernando metafísicos -lo digo por el título de tu artículo, que tampoco entiendo-, no existe quizá nada más metafísico que la formación de los precios en Marx a partir de los valores-trabajo o eso del fetichismo de la mercancía, que yo respeto aunque no comparto ni su explicación ni su validez. Tal es así que se necesita hacer esa transformación de valores a precios (ver Marx, Sraffa y el problema de la transformación, I. Steedman) que una inteligencia como la de el mismo Marx intenta y reconoce su defecto. En efecto, los bienes y servicios (mercancías en Marx) se intercambian por sus precios y no por los valores obtenidos a partir de los capitales contantes, variables y plusvalía. Desde Bortkiewicz ha dado mucho trabajo y mucha literatura tal conversión. Tal es así que se considera los precios de Marx como la primera solución de una cadena de Markov de conversión de valores a precios a partir de las condiciones de Marx, cosa que Marx no podía saber. No es de extrañar las dificultades de la teoría de los precios del alemán. Él mismo explica este hiato entre valores y precios cuando dice que "el precio de costo de una mercancía se refiere solamente a la cantidad de trabajo retribuido que en ella se contiene, mientras que el valor se refiere a la cantidad total de trabajo contenido en ella, tanto al retribuido como al no pagado; el precio de producción, por su parte, se refiere a la suma del trabajo retribuido más una cantidad de trabajo no pagado, independiente de la esfera especial de producción de que se trate"13. Dos precios y un valor. Y con eso hay que tirar si se quiere explicar y -lo que es más importante- incorporar a Marx en el canon, en el corpus de conocimientos de un economista, que no lo está. Observa la

${ }^{13}$ El Capital, tomo III, sección I, cap. IX, pág. 171, FCE, 1974. 
definición de precio de producción -expresión que también usa Sraffa, aunque yo la critico- porque deambula en la misma esfera de realismo que la del italiano, a pesar de no ser iguales. En Sraffa los precios son contables en la medida que se corresponden a tasas únicas (globales) de la producción (por esa los llama... de producción); en Marx también lo son (contables) porque por medio está la plusvalía media -yo así lo sobreentiendo- que permite huir de un mero empirismo a también precios contables, al igual que Sraffa. Ni Sraffa ni Marx son metafísicos; ambos se mueven en niveles de abstracción en este tema -en otros, mucho más Marx que Sraffa, que yo no valoro ni critico- que les permite eludir tres peligros: o una explicación trivial de que todo depende de todo, o un cuasi empirismo en el que se mueve, por ejemplo, el modelo de Leontief, o un mero formalismo sin teoría, como el de Von Neumann.

Finalizas tu artículo señalando que no digo nada de las coincidencias entre el análisis de Sraffa y el marginalismo. Ahí discrepo absolutamente contigo y además no me gusta ser juzgado por supuestas intenciones de las que carezco. Tú mismo enumeras con acierto las diferencias entre el marginalismo y Sraffa a partir de mi artículo. Diré estas: 1) El objetivo principal y núcleo duro (il cuore) de Sraffa es el excedente, mientras que en el marginalismo es la asignación de recursos y formación de los precios; 2) En Sraffa los salarios se reparten una vez determinado el excedente, mientras que en el marginalismo los salarios y ganancias son fruto de supuestas productividades marginales, es decir, de condiciones productivistas y no de la lucha de clases; 3) Sraffa no optimiza, salvo con la excepción de la frontera de salarios-ganancias para pasar de una técnica a otra; en el marginalismo no paran de optimizar, tanto en el consumo (utilidad marginal, relaciones marginales de sustitución), como en la producción (productividades marginales), como en el cálculo de los precios (costes marginales), en una tarea agotadora; 4) para Sraffa el capital es trabajo fechado; para el marginalismo es un factor más de producción, con vida propia y con su consecuente retribución; 5) Sraffa trabaja con modelos desagregados intersectoriales, mientras que los marginalistas agregan en cuanto te das la vuelta, aunque sea lo que ellos entienden por capital. Si lees Descifrando a Sraffa verás el esfuerzo hecho -otra cosa es el resultado- por poner en evidencia las diferencias entre Sraffa y los marginalistas. Aún así te haré una concesión que no has visto, porque es verdad que hay un punto de conexión entre Sraffa y la teoría del capital austríaca y es que ambos analizan el capital fijo en términos de períodos medios de producción. Se puede ver leyendo la importante obra de Garegnani El capital en la teoría de la distribución y el capítulo de Sraffa sobre el capital fijo. Es esta una conclusión mía y no imputable a Garegnani, pero es cierto que no acaba de gustarme.

No quiero se exhaustivo porque esta especie de réplica pretende que sea publicada en la revista digital Nueva Tribuna y ahí los lectores -por suerte para ellos- no son especialistas en todo esto y tienen una visión e interés mucho más amplio. Termino diciendo algo sobre el empleo de las matemáticas, porque para nada la matematización de una teoría o modelo le da a aquélla o a éste marchamo de conocimiento científico; ni siquiera de conocimiento. Tampoco debe ser un obstáculo. Ocurre, no obstante, que para el estudio de la obra de Sraffa Producción de..., son imprescindibles las matemáticas. En concreto, el álgebra matricial. Y no se puede imputar al italiano un abuso del 
uso de este instrumento, porque el esfuerzo explicativo de la lógica económica que lleva a cabo intentando eludir lo formal es encomiable. Tal es así que le lleva a cometer algunos errores, como es el de confundir la tasa máxima de ganancia con la razón-patrón o como cuando cree encontrar un vector de precios positivos sin acudir al teorema de Perron-Frobenius. Si algo se le puede acusar a Sraffa es el de un uso insuficiente de lo formal que le sirva de guía, al menos en lo expositivo. Hay que decir que pocos economistas no matemáticos han estado mejor asesorados que Sraffa y que el agradece mencionándolos en su prólogo (Ramsey, Besicovitch y Watson). Y a pesar de ello renunció a las matemáticas si las conclusiones derivadas de éstas no podían ser explicadas con meros razonamientos económicos, cosa imposible con el teorema de Perron-Frobenius. Por eso ahora toca a los demás lo que no hizo: desarrollar su teoría y completar, complementar y rectificar (con matemáticas o sin ellas) lo que el dejó o erró. Eso ya lo han hecho en parte economistas de la talla de Schefold, Kurz, Pasinetti o Steedman. En este punto sobre el uso adecuado de lo formal no es tan ingenuo ni neutral como creen los que se aferran a los conceptos cual tabla de salvación -no digo que tú lo hagas, Fernando- y no salen de su agarradura. Pondré dos ejemplos para no caer en una disertación abstracta y estéril. Sraffa aborda tanto la producción simple como la conjunta con un vector de precios -distinto en ambos casosque es el mismo tanto para los medios de producción como para los productos finales. La cuestión es discutible porque eso es impensable en el mundo real. No obstante, si lo que se quiere es valorar son los desplazamientos de los métodos de producción o la frontera salario-ganancia, por ejemplo, parece pertinente. Sin embargo resulta inexcusable si partimos de una diferenciación entre bienes básicos y no básicos, porque la conclusión a la que quiere llegar Sraffa es la de que los bienes no básicos dependen de los básicos, pero no al revés. En este caso podemos suponer de entrada que el número de bienes no básicos es distinto de el de los básicos, lo que supone asentar como hipótesis que al menos la matriz de bienes no básicos no es cuadrada y, por lo tanto, no va ser invertible si el número de bienes no básicos es mayor que el de procesos (o sectores). Hecho esto, si ahora quisiéramos llegar a la frontera salarios-ganancia, es decir, a una relación entre estas dos tasas sin que medien los precios, hemos de ingeniarlas para que el numerario empleado -en el que ineludiblemente van a entrar los precios de los no básicos- permita su neutralidad en la medición del excedente y, por tanto, en el reparto entre salarios y ganancias. En el caso de la producción conjunta de Sraffa sin diferenciación entre bienes básicos y no básicos ocurre algo similar y todo se facilita si suponemos que el número de bienes de productos finales cualitativamente distintos es el mismo que el de medios de producción. De lo contrario, lo realista es suponer que el número de los finales es superior al de los medios, pero ello nos trae que la matriz de productos finales no va a ser invertible porque no va a ser cuadrada para obtener el vector de precios de equilibrio. Sraffa era consciente de este problema (ver nota de la pág. 76 de Producción de... ). Otro ejemplo es el del análisis de Bortkiewicz de la transformación de valores a precios. Esta tiene una cierta trampa, porque el economista parte de 3 sectores con 4 variables (tres coeficientes de transformación y la tasa de ganancia). Procede a continuación a tomar como numerario un coeficiente, con lo cual elimina el grado de libertad y puede obtener así unos valores concretos de los otros dos coeficientes y de la tasa de 
ganancia). El truco está en que supone casi tantos sectores como coeficientes. Si ahora generalizamos el número de sectores a $\boldsymbol{n}$, el método Bortkiewicz se nos viene abajo. En los dos ejemplos anteriores lo formal ha condicionado el resultado tanto como los deseos de éste ha empujado al uso de aquél. En ambos casos, ni podemos eludir lo formal ni aceptar cualquier uso de éste. Un ejemplo magnífico de lo que digo es el propio Sraffa, que por más esfuerzos que hizo para dejar lo formal entre bambalinas, aquél aparece continuamente, aunque a veces algo maltrecho.

Tenemos que aceptar que las mal Ilamadas ciencias sociales sólo pueden recibir un tratamiento teorético por medio de modelos. Todos son modelos, desde el de Sraffa -escrito en apenas de 100 apretadas páginas- como el de Marx en las 2000 páginas de El Capital más las del resto de su obra. Incluso en las ciencias físicas también se habla del modelo estándar o de la teoría de la relatividad. Newton fue el último que se atrevió a explicar el sistema del mundo sin explicitar que se trataba de un modelo, sino que creyó que era el modelo, aunque incompleto (aceptaba que no pudiera explicar la causa de la gravitación). Unos modelos serán susceptibles de formalización y otros no (por ejemplo, el psicoanálisis) y, en cualquier caso, siempre se podrá hacer un uso torpe o inteligente del instrumento, oportuno o inoportuno, sustitutivo de lo conceptual o complementario. Pero todo eso depende del talento de cada cual y no es imputable al contenido; no depende del instrumento, sino del intérprete.

Sólo añadir que ha sido un placer discutir contigo y es de esperar que se sumen más estudiosos a la discusión, porque de ésta a veces sale la luz; luz que necesitamos, porque la de los neoliberales -versión política de los neoclásicos- la tienen apagada sin ellos saberlo, y nos están llevando al desastre porque son los que asesoran a los que mandan.

Madrid, 17 de diciembre de 2011

\section{Marx desde Sraffa. Respuesta a Fernando Hugo Azcurra, II parte}

\section{Antonio Mora Plaza}

Quisiera en esta segunda parte abordar de forma original -si algo de talento tengo para ello- el problema de cómo preservar la teoría de la explotación de Marx sin necesidad de pasar por las horcas caudinas de la transformación de valores a precios. No pretendo hacer una historia del problema de la transformación porque eso ya se ha hecho con profusión, aunque me detendré en algún momento en la forma en que lo han abordado, por ejemplo, Ian Steedman y Michio Morishima; y no por afán de cita o apoyo a las tesis que sostendré, sino porque ambos son originales y distintos, casi contrarios. También porque lo que intento no es exactamente lo mismo que ellos. El problema anterior es de segundo nivel respecto al interés mío que es el de responder a la cuestión de si es posible integrar a Marx en los fundamentos de Sraffa. Más precisamente, yo planteo que sí es posible integrar la teoría de la explotación de Marx en la teoría del excedente de Sraffa. Este hecho no se me 
había planteado hasta el artículo que escribió y me mandó Fernando Azcurra, por lo que le estoy agradecido a pesar de su tono crítico contra los artículos sobre los Fundamentos para una nueva teoría económica. Pero ello es provechoso porque se mantiene en el plano intelectual, por así decirlo. Intentaré además distinguir dos planos: 1) el plano de la posibilidad de la integración de la economía de Marx (que aborda multitud de temas) en la teoría limitada de Sraffa, que es la del excedente, de tradición clásica; 2) el plano de mi crítica sobre algunas cuestiones que plantea Marx y que están cerca de las que hace Steedman. En concreto, tengo reservas al menos sobre dos cuestiones: sobre si la teoría de la explotación es sólo propia del sistema capitalista; si es satisfactoria la teoría de la transformación de valores a precios de Marx, incluso subsanada de sus defectos. Tal como yo entiendo la secuencia de Marx desde el punto de vista de la lógica económica ${ }^{14}$ en El Capital es la siguiente: de la teoría de la explotación (plusvalía) a la teoría del valor trabajo, y de ésta a la transformación de valores a precios. Mi opinión es que esta secuencia tiene grados de abstracción diferentes, de tal manera que puede mantenerse el núcleo duro de la teoría de Marx -que es la teoría de la explotación- abandonando la transformación de valores a precios por no reflejar (cosa distinta a identificar) lo suficiente de la realidad una teoría de los precios aceptable. Estamos siempre en el campo de la teoría, porque cualquier explicación de la realidad se mantiene siempre en el otro lado del espejo, en el lado de lo teorético. Pero al menos debe reflejar, aunque sólo al trasluz, esa realidad a pesar del muro infranqueable que es el espejo. No hay que tener miedo de pecar por acercarse a la realidad porque es imposible una explicación empírica, son términos antitéticos, una contradicción en los términos. La realidad sin teoría es mera estadística. Leyendo estos días un libro sobre el gran matemático Gottlob Frege (Introducción a Frege) me he persuadido aún más de que, por más que intentemos acercarnos a la realidad, nunca se puede caer en un empirismo si de lo que se trata es de explicarla. Define Frege algo tan aparentemente empírico como el número -los números- como "una aserción sobre un concepto"15. Lo avanzo para cuando entremos en la formalización del modelo que se pretende. No tengas miedo Fernando, que por más que una teoría como la de Sraffa pueda adecuarse a lo que hacen los comerciantes -calcular los precios mediante un margen sobre los costes-, nunca nos salimos de la explicación, salvo que, claro está, sólo hagamos

\footnotetext{
${ }^{14}$ Aunque también es admisible anteponer la teoría del valor-trabajo a la teoría de la explotación. Esta interpretación tiene la ventaja de la evolución histórica de la teoría del valortrabajo. Sin embargo, en mi opinión, no sería la correcta, porque la teoría de la explotación tiene un grado de abstracción y nuclear en el sistema de Marx más alto y más importante. Y lo presento así, a costa de que pueda interpretarse que rectifico al propio Marx en cuanto al orden de presentación en su obra en ambos temas. De lo que estoy convencido -pero abierto a otras interpretaciones- es que el modelo que desarrolla Marx en El Capital puede sobrevivir sin la teoría del valor-trabajo, pero no puedo hacerlo sin la teoría de la explotación. Y en cuanto al problema de la transformación de valores a precios, mi punto de vista es el contrario: sólo puede sobrevivir la teoría del valor-trabajo si la despojamos de su aspecto contable, es decir, si se abandona el cálculo de los precios mediante la transformación. Decía Einstein que el mayor error de su vida fue la constante cosmológica que había introducido en sus ecuaciones de campo de la relatividad general; análogamente, podríamos decir que el mayor error de Marx en su modelo es forzar un cálculo de los precios basado en la transformación a partir de los valores contables de su teoría del valor.

${ }^{15}$ Introducción a Frege, A. Kenny, edit. Cátedra, 1997, pág. 100 (An Introduction to the Founder of Modern Analityc Philosophy, 1995).
} 
estadísticas. Y sin embargo, esta forma de entender los precios es mucho más cercana que la teoría marginalista basada en igualar los ingresos marginales con los costes marginales, ingresos y costes que la mayoría de los empresarios ni saben conceptualmente lo que es, ni, aun sabiéndolo, podrían calcularlos por falta de información. Volviendo a Marx, acepto íntegra la teoría de la explotación de Marx. Daré una cita del alemán que puede ser significativa de su teoría. Diré antes que en un libro como El Capital podemos encontrar citas no equivalentes, incluso algunas contradictorias, por lo que han de recogerse las que puedan ser representativas. Creo que esta lo es. Dice Marx que "el obrero añade al objeto sobre el que recae el trabajo nuevo valor, incorporándole una cantidad de trabajo, cualesquiera que el contenido concreto, el fin y el carácter técnico de este trabajo sean"16. Entiendo que es el plano objetivo de la explotación, la condición necesaria para la plusvalía, sin entrar todavía en las relaciones de clase que han de establecerse para que el capitalista arranque del obrero esa posibilidad objetiva. Más adelante Marx rebaja el grado de abstracción de lo anterior y se vuelve más explicativo cuando dice que "las masas de valor y de plusvalor producidas por capitales distintos están, suponiendo que se trata de valores dados y de grados de explotación de la fuerza de trabajo, en razón directa a las magnitudes de la parte variable de aquellos capitales, es decir, de las partes invertidas en fuerza de trabajo viva"17. El límite de la plusvalía lo acota Marx cuando señala que "partiendo de una magnitud de población dada, este límite -se refiere la plusvalía- lo traza la posible prolongación de la jornada de trabajo"18. Esta es, por cierto, la interpretación de Morishima (Marx's Economics) para desarrollar formalmente el teorema de Okishio. Aceptada la teoría de la explotación y negado el método de transformación de valores a precios por no ser un reflejo idóneo de la realidad, nos quedaría el estado intermedio, la conexión entre ambos: la teoría del valor trabajo. Traigo a colación un texto de Marx que, en mi opinión, explica como nadie su teoría del valor-trabajo, que, además, no es un texto de El Capital sino de Miseria de la Filosofía: "El valor no es el tiempo en el cual una (mercancía) ha sido producida, sino el mínimo de tiempo en el cual es susceptible de ser producida, y este mínimo se atestigua por la competencia"19. Es un valor contable, hipotético, no el estadístico. Con este texto se aparta de una mera teoría ricardiana del valor-trabajo como el del tiempo necesario para producirlo para desarrollar una teoría de valores contables, donde la competencia juega un papel decisivo. Lo traigo a colación porque lo que viene a continuación supone renunciar a esta consideración sobre la formación de los precios a partir de esta teoría del valor. Es de justicia para valorar lo que se alcanza saber a lo que se renuncia. En todo caso podemos sustituir la idea de valor de Marx en este texto por el de precio y la cosa deja el camino expedito al modelo de Sraffa, donde los precios son fruto de 4 cosas o condicionantes: 1 ) son precios de equilibrio del sistema, 2) son precios de intercambio, 3) son precios obtenidos sobre tasas hipotéticas unitarias de ganancia y salarios, 4) son precios a largo plazo. La ventaja de partir de Sraffa es que estos defectos o limitaciones son subsanables. Lo mejor de ambas teorías, la de los valores (Marx) y la de los precios (Sraffa) es que no son incompatibles si eludimos el

\footnotetext{
${ }^{16}$ El Capital, I vol., FCE, pág. 151.

17 El Capital, I vol., FCE, pág. 245.

18 El Capital, I vol., FCE, pág. 247.

${ }^{19}$ Miseria de la Filosofía, Ediciones Júcar, pág. 116.
} 
tema de la transformación. Para su tratamiento vamos a construir un modelo en el que aceptamos ambas definiciones de valores y precios.

A) Modelo Sraffa-Marx de producción simple

El modelo de Marx vendría dado por la ecuación matricial:

$$
\underset{n \times n}{\operatorname{T}} \underset{n \times n}{Y}=\underset{m x n}{C}+\underset{m x n}{V}+\underset{m x n}{S}
$$

donde $\boldsymbol{T}$ es una matriz de valores (unitarios), cuyo elementos representan el valor-trabajo de la mercancía $\boldsymbol{i}$ (de 1 a $\boldsymbol{n}$ ) procedente del sector o proceso $\boldsymbol{j}$ (de $\mathbf{1}$ a $\boldsymbol{n})$. Los signos $\boldsymbol{C}, \boldsymbol{V}, \boldsymbol{S}$ representarían los capitales constantes, variables y plusvalía de, también, las mercancías $\boldsymbol{i}$ procedentes de $\boldsymbol{j} ; \boldsymbol{Y}$ sería la matriz $\boldsymbol{n} \times \boldsymbol{n}$ de productos finales. Aceptamos también las consideraciones de Marx sobre la composición orgánica de capital $(\boldsymbol{K})$ y la teoría de la explotación $(\boldsymbol{E})$, pero la formalizamos mediante las matrices $\boldsymbol{K}$ y $\boldsymbol{E}$ de $\boldsymbol{n} \times \boldsymbol{n}$ elementos. Ello supone partir de distintas composiciones orgánicas y tasas de explotación por bienes y servicio y sectores (o procesos), pero si se quiere simplificar y hacer iguales las composiciones por mercancía no hay ningún problema; lo mismo con las tasas de explotación. También se puede simplificar por sector hasta convertir las matrices $\boldsymbol{K}$ y $\boldsymbol{E}$ en simples escalares. Con estas consideraciones, las ecuaciones de Marx para composiciones orgánicas y tasas de explotación serían:

$$
\begin{gathered}
\underset{n \times n}{C}=\underset{n \times n}{V} \underset{n \times n}{K} \\
\underset{n \times n}{S}=\underset{n \times n}{\underset{n \times n}{E}}
\end{gathered}
$$

Hasta aquí la formalización de la teoría del valor-trabajo de Marx partiendo de la teoría de la explotación. Del conjunto de las ecuaciones (1), (2) y (3) se obtiene:

$$
T Y=V\left[I_{d}+K+E\right]
$$

donde $I_{d}$ es la matriz diagonal de unos $\boldsymbol{n} \times \boldsymbol{n}$. Hasta aquí lo que aporta Marx al modelo. Ahora traemos a colación el modelo de Sraffa tal como lo presenta el economista italiano en Producción de..., aunque luego lo generalicemos porque a mí me parece demasiado restrictivo.

$$
\begin{aligned}
& P Y=w L+(1+r) P X \\
& P Y=(1+R) P X \\
& P Y I-P X I=1
\end{aligned}
$$


(8)

$$
L I=1
$$

donde $\boldsymbol{P}$ es el vector de precios $\mathbf{1 x n}, \boldsymbol{w}$ la tasa de salarios, $\boldsymbol{L}$ el vector de inputs de trabajo $1 \times n, r$ la tasa de ganancia, $\boldsymbol{X}$ la matriz $\boldsymbol{n} \times \boldsymbol{n}$ de medios de producción y $\boldsymbol{R}$ es la razón-patrón (= a la tasa de ganancia máxima en la producción simple esrafiana). Y ahora viene la ecuación decisiva, la que va a unir el universo de Marx con el de Sraffa, los valores del primero con los precios del segundo sin pasar por la transformación. Es como sigue:

$$
\underset{1 \times n}{P} \underset{n x n}{Y}=\underset{1 \times n}{u} \underset{n x n}{T} \underset{n x n}{Y}
$$

donde $\boldsymbol{u}$ es un vector de transformación de valores a precios. Es una de las dos condiciones que poner Marx para pasar de valores a precios: que el valor de todo lo producido en términos de precios sea igual que en términos de valor. Veremos que no es necesario calcular los coeficientes $\boldsymbol{u}$ porque desaparecerán. Entre (4) y (9) se obtiene:

$$
P=u V\left[I_{d}+K+E\right] Y^{-1}
$$

Y la ecuación (10) nos da los precios en función de la tasa de explotación y composición orgánica de Marx sin pasar por la transformación. Y en (10) cabe toda la teoría de la explotación (E) de Marx. Incluso la teoría del valor-trabajo, porque (10) se ha obtenido a partir de ella (1). Pero sin embargo Sraffa no aparece. Para ello vamos a establecer, no sólo la equivalencia general de Marx entre valores y precios (9), sino las parciales correspondientes a la del valor de los medios de producción y el capital constante, la de las masas de salarios y capital variable, y la de la ganancia total y la plusvalía total (ésta inspirada por Marx).

$$
\begin{aligned}
& \underset{1 \times n}{P} \underset{n \times n}{X}=\underset{1 \times n}{u} \underset{m \times n}{C} \\
& w \underset{1 \times n}{L}=\underset{1 \times n}{u} \underset{n \times n}{V} \\
& r \underset{1 \times n}{P} \underset{X x n}{X}=\underset{1 \times n}{u} \underset{S \times n}{S}
\end{aligned}
$$

De entre (10) y (12) sale:

$$
P=w L\left[I_{d}+K+E\right] Y^{-1}
$$

Ahora en (14) ya va asomando la patita -la tasa de salarios $\boldsymbol{w}$ - de Sraffa, pero aún no es suficiente. Del conjunto de ecuaciones (5), (6), (7) y (8) obtenemos la ecuación de la razón-patrón de Sraffa para la producción simple: 


$$
w=\frac{R-r}{R}
$$

Y ahora entre (14) y (15) sale:

$$
P=\frac{R-r}{R} \times L\left[I_{d}+K+E\right] Y^{-1}
$$

¡Y ahora sí hemos relacionado los precios con la tasa de explotación marxiana $(E)$ y con la razón-patrón esrafiana $(\boldsymbol{R})$ ! Es verdad que no están los salarios, pero estos aparecen implícitos en las tasas de explotación $\boldsymbol{E}$. De (16) haremos algunas observaciones: 1 ) Se puede observar que si la tasa de ganancia $r$ es cero, los precios son proporcionales a los valores $\left(I_{d}+K+E\right)$, tal como señala la tradición clásica, desde Ricardo a Sraffa pasando por Marx; 2) Los precios son inversamente proporcionales a la productividad del trabajo $\left(L Y^{1}\right)$, pero mediatizados por las composiciones orgánicas $(\boldsymbol{K})$ y las tasas de explotación $(E)$; 3) Los precios son proporcionales a los salarios $\boldsymbol{w}$ (ecuación 14). Si estamos en la producción simple, los precios $\boldsymbol{P}$ serán estrictamente positivos porque la matriz inversa $Y$ de productos finales es positiva por ser una matriz diagonal; en cambio no podemos asegurar eso en la producción conjunta porque $Y$ no sería diagonal y su inversa no necesariamente positiva. Ahora, a partir de (14) podemos obtener la frontera salario-tasa de explotación, equivalente a la de salario-ganancia. En efecto, si post-multiplicamos (14) por $Y$ y despejamos $\boldsymbol{w} / \mathbf{P Y I}$ sale:

$$
\frac{w}{P Y I}=\frac{1}{L\left[I_{d}+K+E\right] I}
$$

La ecuación (17) nos dice al menos tres cosas: 1) que la tasa de salario es la más alta posible si las tasas de explotación $E$ valen cero; 2) que por más que aumente la tasa de explotación, la tasa de salarios no llegará a cero; 3) que la tasa de salario real (w/PYI) será menor cuanto mayor sean los precios de equilibrio calculados de forma autónoma en el sistema de precios de Sraffa. En realidad ahora la suma del valor de los bienes y servicios finales (PYI) actúa como numerario, razón por la cual ya no tenemos la relación de la razón-patrón (15), lo cual no cambia el fondo de la cuestión. 


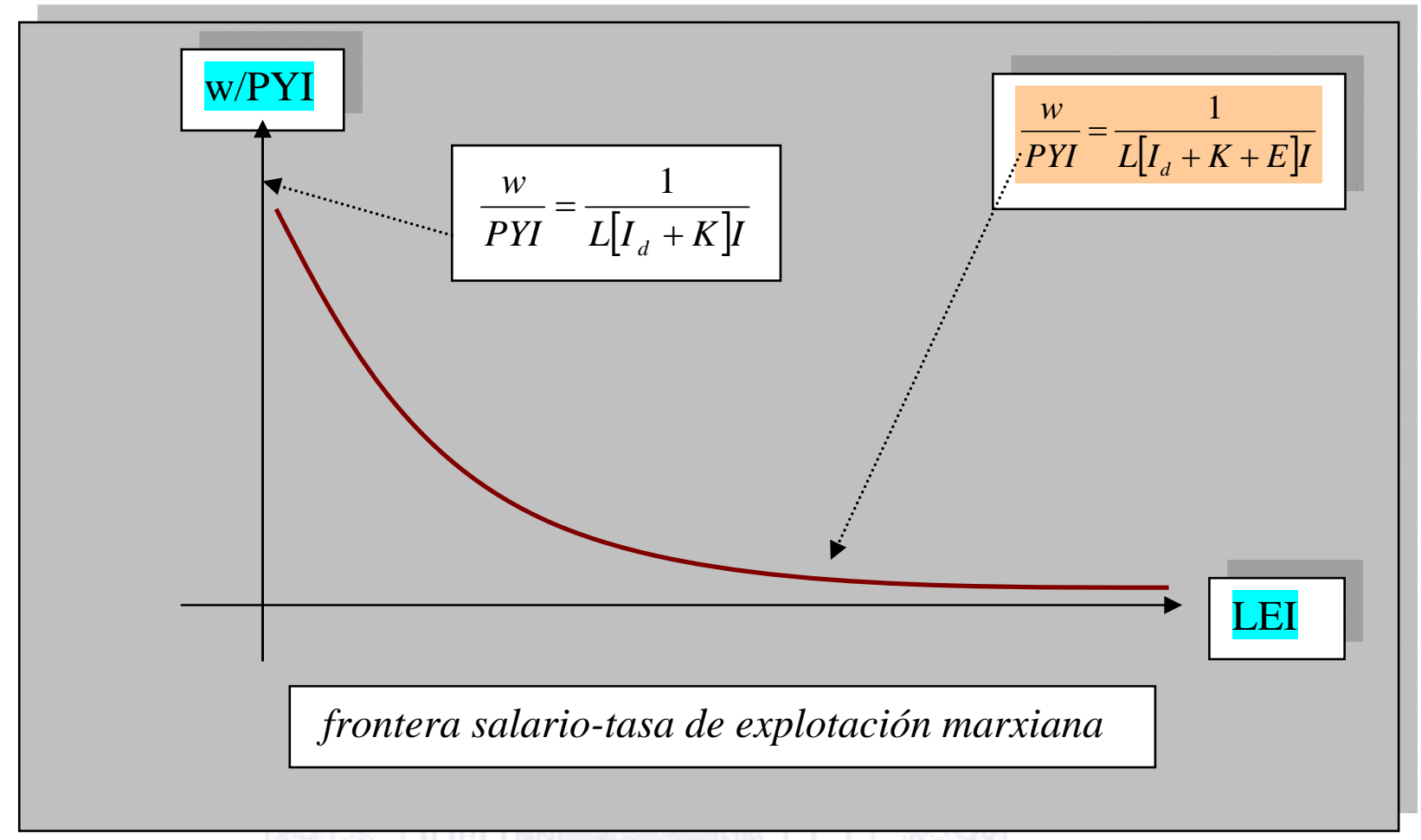

B) Modelo Sraffa-Marx de producción conjunta generalizada

La ecuación que define la producción conjunta a partir de Sraffa pero con salarios pre-factum es como sigue:

$$
\underset{1 \times n}{P} \underset{n \times n}{Y}=\lfloor\underset{1 \times n}{L} \underset{n \times n}{W}+\underset{1 \times n}{P} \underset{n \times n}{X}\rfloor\left(I_{d}+G\right)
$$

A partir de ésta obtenemos la ecuación de la tasa máxima haciendo cero los salarios:

$$
P Y=P X\left(I_{d}+G_{m}\right)
$$

Con las dos anteriores se obtiene la ecuación de precios:

$$
P=L W\left(I_{d}+G\right)\left(G_{m}-G\right) X^{-1}
$$


Ahora ponemos la ecuación inspirada en el $2^{\circ}$ criterio de Marx tal que la suma de las ganancias se iguala con el total de las plusvalías:

$$
[L W+P X] G I=U S I
$$

Y el cuadro está completo con las ecuaciones (1), (13), (20) y (21) se obtiene:

$$
L W\left[I_{d}+\left(I_{d}+G\right)\left(G_{m}-G\right)^{-1}\right] G I=L W E I
$$

que relacionan entre si las múltiple tasas de explotación marxianas con las tasas máximas de ganancia esrafianas. Salarios, ganancias e inputs serían comunes. No tenemos la razón-patrón porque estamos en la producción conjunta. Para facilitar la visualización de la relación implicada en (22) vamos a pasar a tasas unitarias de ganancia $(\boldsymbol{g})$, ganancia máxima $\left(\boldsymbol{g}_{\mathrm{m}}\right)$ y de explotación (e), pero no obtenidas de forma arbitraria, sino a tasas obtenidas por las 3 ecuaciones:

$$
\begin{aligned}
& L W\left[I_{d}+\left(I_{d}+G\right)\left(G_{m}-G\right)^{-1}\right] G I=\frac{w(1+(1+g)) g}{g_{m}-g} L I \\
& L W E I=e w L I \\
& P X\left(I_{d}+G_{m}\right) I=\left(1+g_{m}\right) P X I
\end{aligned}
$$

Hecho eso, la (22) se convierte en:

$$
\left(g_{m}-g\right)(e-g)=(1+g) g
$$

y despejada la tasa de ganancia queda:

$$
g=\frac{g_{m} e}{1+g_{m}+e}
$$

y hemos llegado a una forma modificada del teorema de Okishio-Morishima (O$\mathrm{M})^{20}$ : que la condición necesaria y suficiente para que la tasa de ganancia (esrafiana) sea positiva es que la tasa de explotación (marxista) lo sea también. Hay que recordar que el teorema de O-M se refiere a la condición de precios positivos, pero ésta es plenamente marxista y obtenida a partir de la tasa de explotación de Marx sin ningún condicionante. Y (27) se cumple para cualquier nivel de precios, cualesquiera que sean los medios de producción, los productos finales y los capitales constantes. Se puede demostrar (ver

\footnotetext{
20 "Para que exista un conjunto de precios positivos es necesario y suficiente que se de un tipo de salarios reales tal que el grado de explotación sea positivo": A matematical Note on Marxian Theorems, Okishio.
} 
Descifrando a Sraffa) que la tasa de ganancia máxima $\boldsymbol{g}_{\mathrm{m}}$ depende de los medios y productos finales en la forma de $\boldsymbol{g}_{\mathrm{m}}=\boldsymbol{f}\left(\boldsymbol{X}^{-1}(\boldsymbol{Y}-\boldsymbol{X})\right)$, con lo que la tasa de ganancia puede ser expresada como:

$$
g=\frac{f\left(X^{-1}(Y-X)\right) e}{1+f\left(X^{-1}(Y-X)\right)+e}
$$

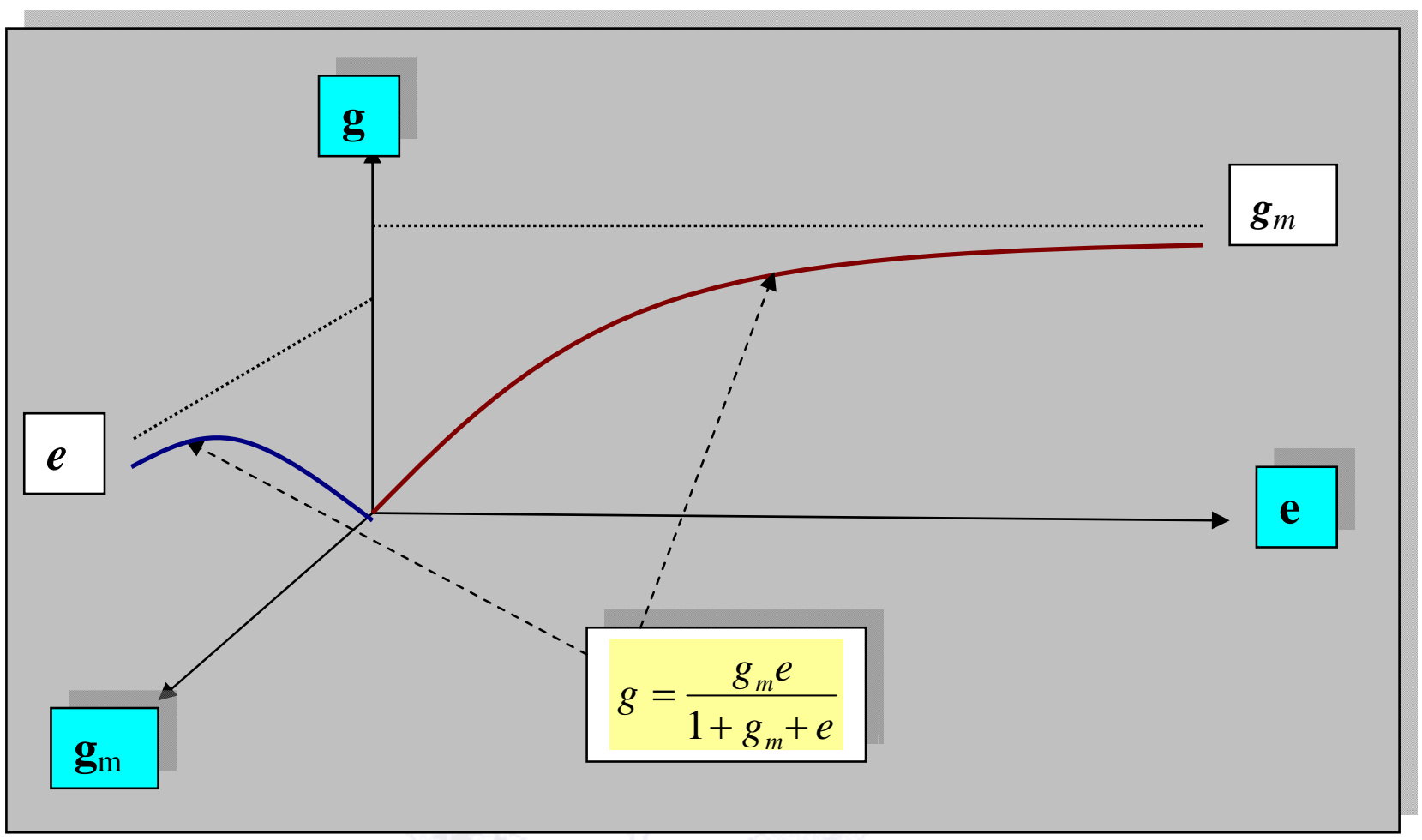

Los salarios han desaparecido porque están subsumidos en la tasa de explotación, y la tasa de ganancia sólo depende de dos de las tres las variables no monetarias de Sraffa (medios y productos finales). Es verdad que con ello ha desaparecido el grado de libertad entre salarios y ganancias que es -en mi opinión- una de las tres condiciones necesarias para ser considerado un modelo como esrafiano, pero el hecho es inevitable porque se ha añadido una condición adicional: la tasa de explotación de Marx. Es el precio que hay que pagar por embutir la teoría de la explotación de Marx en la teoría del excedente de Sraffa. 
C) La dificultad de la teoría de la explotación

Vistos los dos epígrafes anteriores parecería que la teoría de la explotación de Marx hubiera salido triunfante en su enfrentamiento con Sraffa salvo las dos heridas antes apuntas: la pérdida del grado de libertad del modelo del italiano y la renuncia a la teoría de la transformación de valores a precios de Marx. Incluso que el teorema de Okishio-Morishima no tuviera problemas y que la teoría de la plusvalía de Marx descansara sólo -como nos dice Morishima y un texto de Marx- en la mera prolongación de la jornada de trabajo. La cosa no es tan sencilla porque veremos ahora que todo lo anterior es sólo un caso particular, se debe a un supuesto que hemos hecho que es más que cuestionable. Este viene definido por la ecuación (21). Es decir, siguiendo el segundo criterio de Marx para relacionar precios y valores (unitarios), hemos supuesto que el valor de las ganancias obtenidas a partir de los precios (de Sraffa) es igual al valor de la plusvalía obtenida a partir de los valores-trabajo (de Marx), mercancía a mercancía. Supongamos que eliminamos este supuesto y nos deshacemos de la igualdad (21). Nos queda ahora las ecuaciones esrafianas y marxianas siguientes:

$$
\begin{aligned}
& \underset{n \times n}{T} \underset{n \times n}{Y}=\underset{n \times n}{C}+\underset{n \times n}{V}+\underset{m \times n}{S} \\
& \underset{n \times n}{C}=\underset{n x n}{V} \underset{n \times n}{K} \\
& \underset{n \times n}{S}=\underset{n \times n}{\operatorname{Exn}} \underset{ }{E} \\
& \underset{1 \times n}{P} \underset{n \times n}{Y}=\underset{1 \times n}{u} \underset{n \times n}{T} \underset{n \times n}{Y} \\
& \underset{1 \times n}{P} \underset{n \times n}{Y}=(1+g)[w \underset{1 \times n}{L}+\underset{1 \times n}{P} \underset{n \times n}{X}] \\
& P Y=\left(1+g_{m}\right) P X
\end{aligned}
$$

Las 3 primeras ya las hemos discutido y corresponden a la modelización de la teoría del valor-trabajo de Marx (29), a la compasión orgánica de capitales (30) y a la teoría de la plusvalía (31). La (32) es en enlace entre los precios de Sraffa y los valores de Marx. Por último, la (33) es la definición del sistema esrafiano pero con salarios pre-factum, mientras que la (34) surge de hacer cero la tasa de salarios en (33), con $\boldsymbol{g}_{\mathrm{m}}$ como tasa máxima de ganancia (la gran aportación de Sraffa al modelo integrado). Pues bien, si integramos este conjunto de ecuaciones en una sola y dejamos la tasa de ganancia $\boldsymbol{g}$ como variable dependiente queda:

$$
g=\frac{g_{m} \times u V\left[I_{d}+K+E\right] I-w L X^{-1} Y I}{u V\left[I_{d}+K+E\right] I+w L X^{-1} Y I}
$$


Por supuesto que para poder despejar la tasa de ganancia hicimos el supuesto de que:

$$
P Y I=g_{m} u V\left[I_{d}+K+E\right] I=\frac{w(1+g)}{g_{m}-g} \times L X^{-1} Y I
$$

es decir, igualamos en términos de valores totales (no mercancía a mercancía) precios esrafianos con valores marxianos. Ya hemos dicho que la gran ausente de (35) es la (21), es decir, la que permite igualar ganancias esrafianas con plusvalías marxistas. Pero en (35) la sorpresa es terrible porque esta ecuación nos dice que ila tasa de ganancia $g$ puede ser positiva aun cuando las tasas de explotación $\boldsymbol{E}$ sean cero! En efecto, con esta consideración (35) queda:

$$
g(E=0)=\frac{g_{m} \times u V\left[I_{d}+K\right] I-w L X^{-1} I}{u V\left[I_{d}+K\right] I+w L X^{-1} Y I}
$$

Y (37) valdrá cero para el caso particular de que la tasa de salarios $\boldsymbol{w}$ y los capitales variables estuvieran en relación tal como:

$$
w(g=0 ; E=0)=\frac{g_{m} \times u V\left[I_{d}+K\right] I}{L X^{-1} Y I}
$$

¡que sólo lo será por casualidad! La tasa de salarios no ha de ser una tasa cualquier sino aquella que surja de las ecuaciones (23), (24) y (25) si partimos de un sistema formal de ecuaciones con $\boldsymbol{n} \times \boldsymbol{n}$ tasas de explotación, ganancia, salarios y ganancias máximas. Nada pues de tasas arbitrarias, sino a partir de datos tomados de la realidad (realidad, Fernando, como fenómeno, no como noúmeno kantiano). Ahora, para evitar que se nos derrita Marx hemos de suponer que (38) se cumple siempre. O al menos para que se cumpla la interpretación de Morishima de la economía de Marx y partir del teorema de Okishio-Morishima reflejado parcialmente en (27). En el epígrafe anterior y para que se cumpla el teorema hemos supuesto (ahora lo sabemos) que ha de cumplirse (38). En todo caso, si obligamos a que se cumpla (38) - que es una ecuación determinística de los salarios en función de las composiciones orgánicas, de los capitales variables, de la tasa máxima de ganancia esrafiana y de las variables no monetarias esrafianas del trabajo, medios y productos finales- hemos perdido la tasa de ganancia (implícita en el capital variable $\boldsymbol{V}$ ); y hemos perdido con ello el grado de libertad esrafiano del excedente entre salarios y ganancias. Sabíamos que eso era inevitable si introducíamos las nuevas condiciones sobre las tasas de explotación (aun cuando obviemos las composiciones orgánicas, es decir, aun cuando sustituyamos en (35) la matriz de esta composiciones por los capitales constantes directamente, es decir, aun cuando nos olvidemos de la ecuación (30)). Visto desde mi punto de vista en cuanto que Sraffa ha de constituir los fundamentos de una nueva teoría económica, la pregunta es: ¿merece la pena acabar con una de las tres patas del banco de estos fundamentos esrafianos a cambio de introducir la teoría de la explotación de Marx? Lo dejo en el aire. Hay siempre una solución: suponer 
que el salario esrafiana $\boldsymbol{w}$ y los capitales variables marxianos $\boldsymbol{V}$ son tales que (38) se cumple siempre por definición de capital variable. Pero si aceptamos eso, la cuestión que se plantea es que esa relación parece que ha de cumplirse no sólo en el modo de producción capitalista (visión de Marx), sino en cualquier otro (versión antimarxista). Un dilema que parece insoluble.

Observando (35) puede darse el caso de ganancias positivas con plusvalías negativas. La primer vez que contemplé esta posibilidad la deseché por creer que carecía de fundamento en el marco de una teoría de la explotación. Sin embargo, cuando leí posterioremente hace ya algunos años a Steedman me hizo reconsiderar la cuestión. Dice Steedman que "la plusvalía, definida como el total del trabajo vivo menos el total del trabajo incorporado en los salarios incorporado en los salarios reales de los trabajadores, resultará negativo aunque la tasa de ganancia y los precios de producción sean positivos" ${ }^{\prime 2}$. Lo que plantea Steedman es de hondo calado y apenas me atrevo a decir algo al respecto. El texto anterior viene a decir que si el valor -en términos de valortrabajo marxiano- de los bienes que consumen los asalariados (obreros si se quiere) es superior al valor que ellos generan en el proceso productivo, es inobjetable que la plusvalía (absoluta) es negativa. Pero eso choca con la concepción del propio Marx de que la plusvalía es la diferencia entre el valor de la fuerza de trabajo (el retribuido) y el valor incorporado con su trabajo al producto final. Esta última puede ser entendida como un cociente y de tal manera que el denominador es la causa del numerador, lo cual impediría siempre que la plusvalía fuera negativa. Esta es al menos mi interpretación de la plusvalía marxista. Ocurre que la interpretación de Steedman tampoco puede ser desechada por marxista, con lo cual entramos en un problema de coherencia interna del texto del alemán. Yo no me pronuncio al respecto, pero dejo ahí planteada la cuestión. Cuestión, por otro lado, que ha sido puesta en evidencia cuando pasamos de los conceptos y las ideas a estructuras de conocimiento que -afortunadamente en este caso- pueden ser objeto de formalización. Señalar que esta posible conclusión que se desprende de la ecuación (35) se ha obtenido por vía distinta de la de Steedman, pero no deja de ser significativo obtener las mismas conclusiones partiendo de interpretaciones distintas del texto de Marx.

\section{D) La visiones de Morishima y Steedman: una paradoja}

Morishima hace depender la tasa de explotación sólo de la posibilidad de prolongar la jornada de trabajo. La razón de ello es que concibe la posibilidad de partir la jornada de trabajo en función de los dos valores que le atribuye Marx: como valor del trabajo y como valor de la fuerza de trabajo (salario) ${ }^{22}$; como valor de uso y como valor de cambio. Dice Morishima que: "el problema de la determinación del grado de explotación se reduce al de la determinación de la jornada de trabajo"23. Es posible encontrar textos de Marx que avalen esta manera de pensar tal y como hemos hecho en un epígrafe anterior. El problema de ello es que si se demuestra que el teorema de de OkishioMorishima sólo es cierto bajo esa condición (tal y como hemos hecho en el

\footnotetext{
${ }^{21}$ Ver pág. 154 de Marx, Sraffa y el problema de la transformación, edit. FCE.

22 Ver pág. 448 de El Capital (I vol., sección sexta: el salario).

${ }^{23}$ La teoría Económica de Marx, edit. Tecnos, 1977 (Marx's Economics, 1973).
} 
epígrafe anterior), la teoría de la plusvalía de Marx se viene abajo. Sólo si consideramos que la diferenciación entre el valor de uso y de cambio, entre trabajo y valor de la fuerza de trabajo es relativa y no absoluta podemos asegurar que, sea cual sea la jornada de trabajo, hay explotación. Si se aceptara la tesis de Morishima pasarían dos cosas: 1) si la jornada se reduce hasta un cierto límite dejaría de haber explotación; 2) en todo caso, si todo el aspecto cuantitativo de la teoría de la explotación se redujera a la posibilidad de la prolongación de la jornada de trabajo, nada garantizaría que la teoría de la explotación fuera sólo propia del sistema capitalista. Afortunadamente se puede rebatir a Morishima (ver mi Aspectos de la economía de Marx). Morishima hace un mal uso de las matemática y sustituye el concepto de explotación que ha de darse siempre en el sistema capitalista de acuerdo en general con Marx -salvo su desafortunado texto sobre la jornada de trabajoporque el grado es una cuestión de cociente y no de suma. Marx expresa los cocientes entre plusvalía y capital variable, plusvalía y valor de la fuerza de trabajo, y trabajo excedente y trabajo necesario ${ }^{24}$ como equivalentes y como índices de la tasa de explotación. Y si no queremos que Marx desaparezca ante nosotros por el desagüe debemos pensar que los diversos numeradores de estos cocientes vienen causados por los denominadores. Morishima no lo piensa así y toma el texto literal de Marx. Cree con ello reafirmar la teoría de la explotación de Marx, cuando en realidad cava la tumba del alemán sin darse cuenta.

El punto de partida de Steedman sobre Marx es la contraria. Dice por ejemplo que "la solución del problema de la transformación ofrecida por Marx es por entero inaceptable; es internamente incoherente aun cuando se transformen los precios en insumos" 25 . Yo sólo me quedo con la primera parte de la crítica, pero no con la segunda. De hecho, ya sabemos que ese proceso de transformación de Marx de valores a precios es sólo la primera solución de una cadena de Markov a partir de las condiciones de Marx. Marx calcula la plusvalía de cada sector (podría ser de cada mercancía) en función del capital variable y luego reparte proporcionalmente la suma de las plusvalías a la suma de los capitales constante y variable de cada sector (podría ser mercancía). En el mundo real nada es parecido a eso, porque ello supondría que las empresas, cuando calculan su ganancias, deberían saber la plusvalía global del sistema; tampoco se ve por qué habrían de obrar así para poner los precios en lugar de tener en cuenta sus costes y sus posibles ingresos, y sólo los suyos. No se ve por ningún lado las fuerzas del sistema que llevaran a un cálculo de los precios a partir de esa manera de sumar a los costes (en términos de valores marxianos, los capitales constantes y variables) las plusvalía repartidas con el criterio mencionado. Steedman no lo cuenta así, pero así es como hay que sobreentenderlo. Lo que pasa es que no es incoherente, sino falso, inadecuado, no refleja -ni como reflejo- la realidad. Lo de inaceptable en la cuestión de los precios viene porque, calculado los precios como transformación de valores como antes se ha señalado, sólo por casualidad puede coincidir con un sistema en el que -como hace Sraffa- aquéllos (los precios) depende de los medios de producción fechados en el tiempo y de la

\footnotetext{
${ }^{24}$ Pág. 444 de El Capital (I vol., cap. XVI).

${ }^{25}$ Pág. 35 de Marx, Sraffa y el problema de la transformación, FCE, 1985 (Marx after Sraffa, 1977).
} 
parte del excedente que se llevan los salarios. Steedman tira del teorema de Perron-Frobenius a partir de la ecuación de definición del sistema $\boldsymbol{P Y}=$ $(\mathbf{1}+\boldsymbol{r})(\boldsymbol{w} \boldsymbol{L}+\boldsymbol{P X})$. Nosotros hemos igualado valores unitarios y precios en la ecuación (9), y por ello ha resultado la ecuación (16) de determinación de los precios en función de las composiciones orgánicas de capital, de las tasas de explotación (o unitarias si se quiere), del trabajo directo, de la tasa de ganancia, de la razón-patrón de Sraffa y de los productos finales. Ello nos ha permitido dar una versión reducida del teorema de Okishio-Morishima, pero a costa de pagar dos peajes: 1) perder el grado de libertad esrafiano entre salarios y ganancias; 2) abandonar de una vez para siempre el cálculo de los precios a partir de la transformación de valores. Cada uno -Sraffa y Marx- han cedido una parte para poder integrarlos. Por un procedimiento análogo al nuestro aunque no enteramente igual- Steedman llega a la misma fórmula que la nuestra en la determinación de la tasa de ganancia ${ }^{26}$. Cuando di con esta formulación -ecuación (27)- no recordaba esta parte de la obra de Steedman, lo cual me llenó de satisfacción porque ambos habíamos llegado al mismo resultado por caminos diferentes. Y esta fue doble porque con ello se consigue dos cosas: 1) salvar la teoría de la explotación de Marx; 2) hacer depender las ganancias sólo de la tasa de explotación. La paradoja está servida: en apariencia Steedman ataca con dureza la teoría de la transformación de Marx para el cálculo de los precios y con ello salva el núcleo de la teoría de Marx; Morishima, queriendo salvar todo Marx a partir de la plusvalía como prolongación de la jornada de trabajo, le crea al alemán un problema insoluble. Hay ciertamente amistades peligrosas.

\section{E) A modo de conclusiones}

Podríamos resumir todo el artículo de la siguiente manera: 1) La teoría de la transformación de valores a precios de Marx en inasumible porque no se adecua en el plano teorético a un comportamiento sociológico de los actores supuestamente implicados. A ello le añade Steedman que es incoherente, tesis que no se trae a colación, es decir, ni se demuestra ni se refuta; 2) Se acepta entera la teoría de la explotación de Marx y se integra en la teoría del excedente de Ricardo; 3) El punto anterior tiene un doble peaje: a) hay que renunciar al grado de libertad entre salarios y ganancias de Sraffa, b) hay que renunciar también a la parte contable de la teoría del valor-trabajo de Marx para ser sustituida por la de la formación de los precios de Sraffa; 4) Con ambas renuncias se puede mantener íntegra la teoría de la explotación de Marx dentro de la teoría del excedente de Sraffa; 5) El resultado final es un modelo integrado y coherente de 3 elementos (teoría del excedente, de la explotación y de los precios) que no es ni plenamente esrafiano ni plenamente marxista, pero que conserva el núcleo duro de ambos.

Este artículo ha de entenderse como la segunda parte del titulado Sraffa y la teoría del excedente, de tal forma, que este segundo no tiene sentido sin el primero. He intentado en ambos hablar de teoría económica con apoyo de las

\footnotetext{
${ }^{26}$ Pág. 122 de Marx, Sraffa y el problema de la transformación.
} 
matemáticas y no de construir un mero modelo matemático con conceptos económicos. No sé si lo he conseguido.

Madrid, 29 de diciembre de 2011.

1 - Transformación de valores a precios

\section{cuadro}

$\underline{1} \quad$ Valores: entrada de datos

\begin{tabular}{|c|c|c|c|c|c|c|c|c|}
\hline & $\mathrm{K}$ & $\mathrm{V}$ & $S$ & $\begin{array}{l}\text { valor } \\
\text { total }\end{array}$ & cantidades & t. gan. & $\begin{array}{c}\text { t. } \\
\text { explot. }\end{array}$ & $\mathrm{C} / \mathrm{V}$ \\
\hline 1 & 225 & 90 & 60 & 375,0 & 355 & 0,19 & 0,67 & 2,50 \\
\hline 2 & 100 & 120 & 80 & 300,0 & 340 & 0,36 & 0,67 & 0,83 \\
\hline 3 & 50 & 90 & 60 & 200,0 & 180 & 0,43 & 0,67 & 0,56 \\
\hline & 375 & 300 & 200 & 875,0 & & 0,30 & 0,67 & 1,25 \\
\hline
\end{tabular}

cuadro

$\underline{2}$

Solución histórica de Marx

precios $\mathrm{x}$

t.

\begin{tabular}{|c|c|c|c|c|c|c|c|c|}
\hline & K & V & $\mathrm{S}$ & $\mathrm{Q}$ & precios & t. gan. & explot. & $\mathrm{C} / \mathrm{V}$ \\
\hline 1 & 225,0 & 90,0 & 93,3 & 408,3 & 1,150 & 0,30 & 1,04 & 2,50 \\
\hline 2 & 100,0 & 120,0 & 65,2 & 285,2 & 0,839 & 0,30 & 0,54 & 0,83 \\
\hline 3 & 50,0 & 90,0 & 41,5 & 181,5 & 1,008 & 0,30 & 0,46 & 0,56 \\
\hline
\end{tabular}



$375,0 \quad 300,0 \quad 200,0 \quad 875,0$
$0,30 \quad 0,67$
1,25

Cuadro

$\underline{3}$

Solución correcta según Marx

precios $\mathrm{X}$

t.

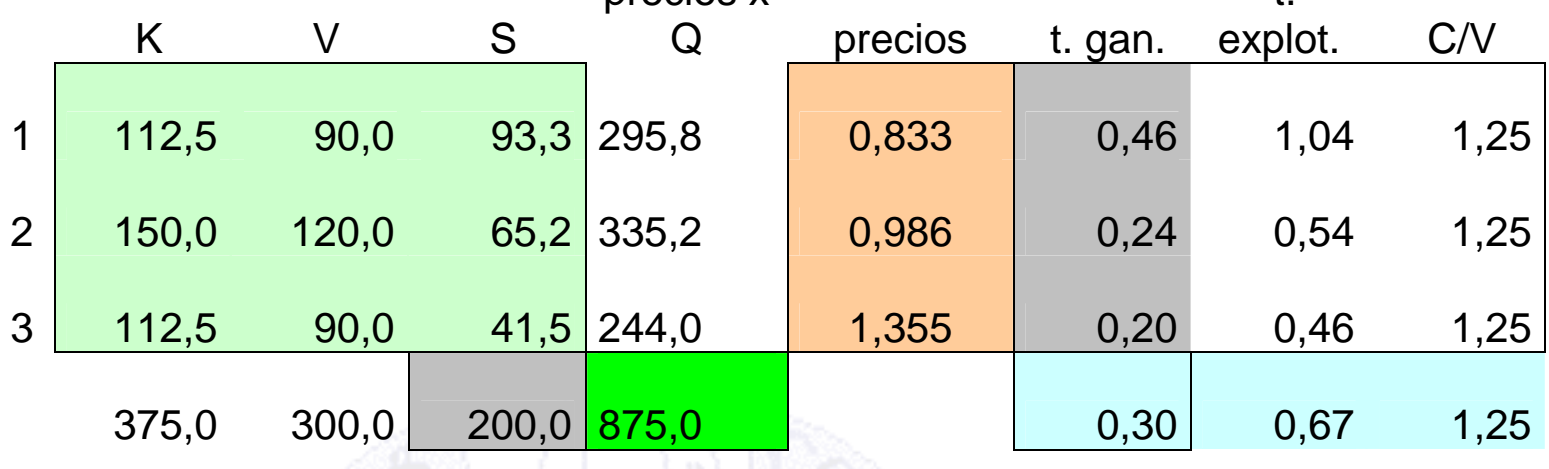

\section{Cuadro}

$\underline{4}$

Solución histórica de Bortkiewicz

\begin{tabular}{|c|c|c|c|c|c|c|c|c|}
\hline & $\mathrm{K}$ & V & $S$ & $\begin{array}{c}\text { precios } x \\
\mathrm{Q}\end{array}$ & precios & t. gan. & $\begin{array}{c}\text { t. } \\
\text { explot. }\end{array}$ & $\mathrm{C} / \mathrm{V}$ \\
\hline 1 & 288 & 96 & 96 & 480,0 & 1,352 & 0,25 & 2,50 & 3,00 \\
\hline 2 & 128 & 128 & 64 & 320,0 & 0,941 & 0,25 & 1,67 & 1,00 \\
\hline 3 & 64 & 96 & 40 & 200,0 & 1,111 & 0,25 & 1,47 & 0,67 \\
\hline & 80 & 320 & 200 & $1.000,0$ & & 0,25 & 1,92 & 1,50 \\
\hline
\end{tabular}

cuadro

$\underline{5} \quad$ Solución normalizada de Bortkiewicz

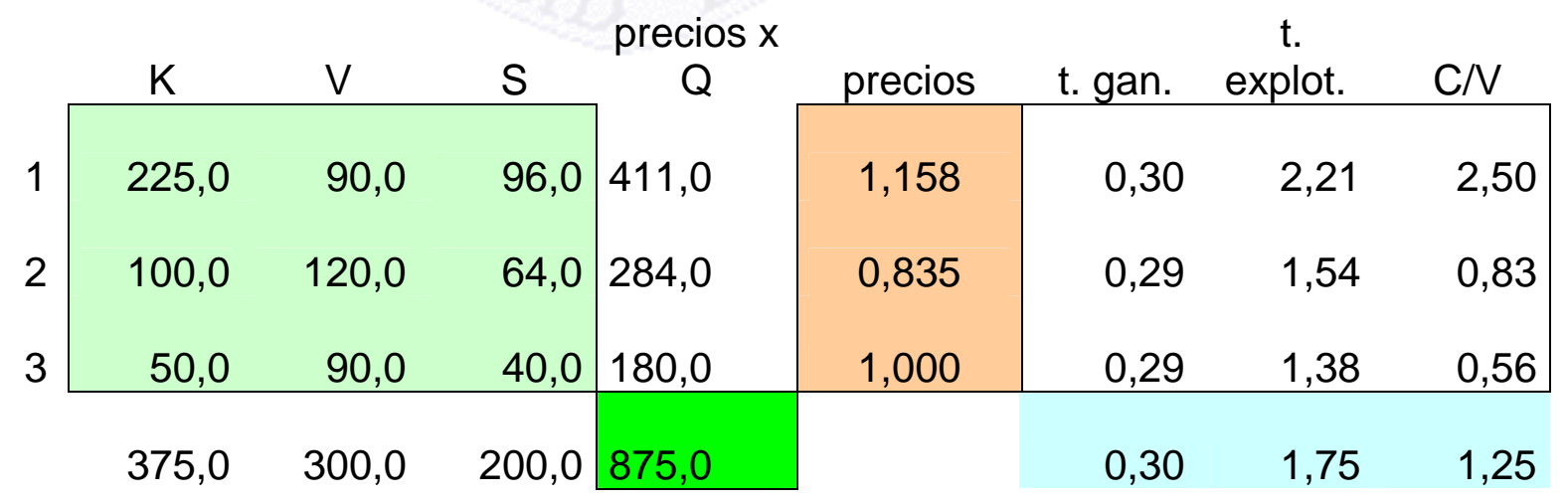

$\underline{\text { cuadro }}$

$\underline{6}$

Solución proporcional a las sumas

$\mathrm{K} V \mathrm{~V}$ precios $\mathrm{x}$ precios t.gan. $\mathrm{t}$. $\mathrm{C} / \mathrm{V}$ 


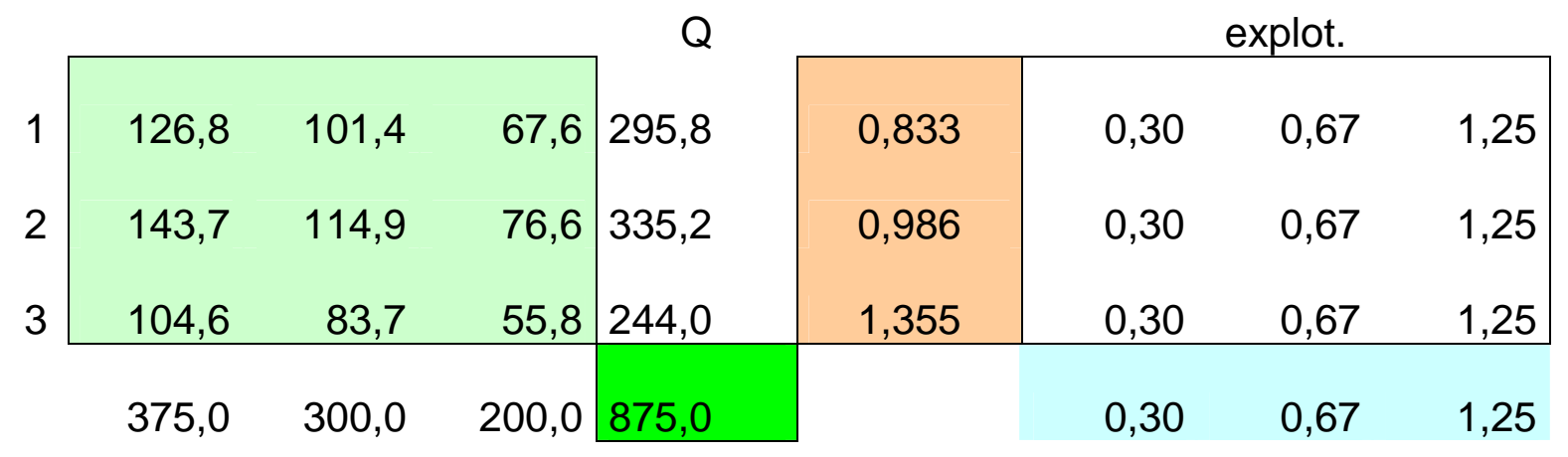

El primer y cuarto cuadros son los datos originales de Marx y Bortkiewicz; el cuadro 2 es la solución de Marx; el cuadro 3 sería la solución correcta si se cumplieran las dos condiciones de Marx; el cuadro 5 es la solución de Bortkiewicz normalizada a las sumas de los capitales constante, variable y plusvalía originales; el cuadro 6 es la solución proporcional a la sumas de la que trata el epígrafe 6 del artículo.

\section{2 -Transformación de valores a precios y coeficientes}

cuadro

$\underline{\underline{1}} \quad$ Valores (datos originales)

\begin{tabular}{|c|c|c|c|c|c|c|c|c|}
\hline & $\mathrm{K}$ & V & S & $\begin{array}{l}\text { valor } \\
\text { total }\end{array}$ & cantidades & $\begin{array}{c}\text { t. } \\
\text { ganan. }\end{array}$ & $\begin{array}{c}\text { t. } \\
\text { explot. }\end{array}$ & $\mathrm{C} / \mathrm{V}$ \\
\hline 1 & 225 & 90 & 60 & 375,0 & 355 & $19,0 \%$ & 0,67 & 2,50 \\
\hline 2 & 100 & 120 & 80 & 300,0 & 340 & $36,4 \%$ & 0,67 & 0,83 \\
\hline 3 & 50 & 90 & 60 & 200,0 & 180 & $42,9 \%$ & 0,67 & 0,56 \\
\hline & 375 & 300 & 200 & 875,0 & & $29,6 \%$ & 0,67 & 1,25 \\
\hline
\end{tabular}

cuadro

$\underline{2} \quad$ Solución histórica de Marx

Coeficientes de transformación

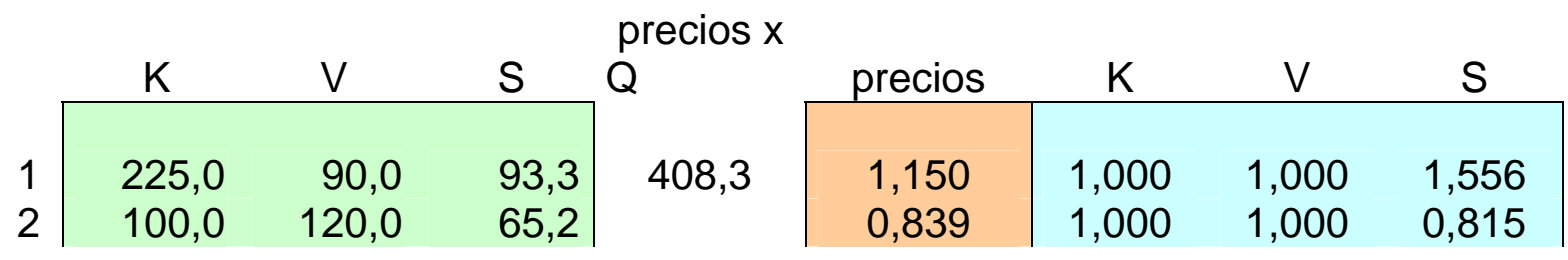




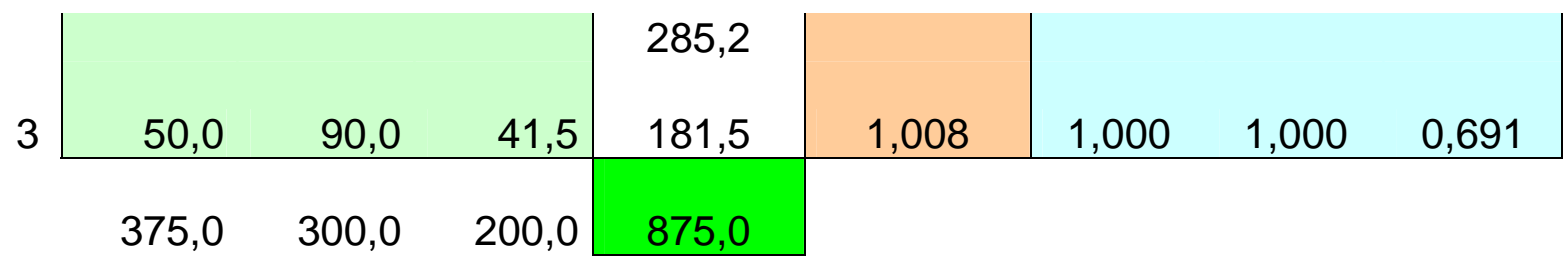
cuadro Solución correcta según $\underline{3} \quad$ Marx

Coeficientes de

\begin{tabular}{|c|c|c|c|c|c|c|c|c|}
\hline & & & & & & & & \\
\hline & K & V & S & $\mathrm{Q}$ & precios & K & V & S \\
\hline 1 & 112,5 & 90,0 & 93,3 & 295,8 & 0,833 & 0,500 & 1,000 & 1,556 \\
\hline 2 & 150,0 & 120,0 & 65,2 & 335,2 & 0,986 & 1,500 & 1,000 & 0,815 \\
\hline 3 & 112,5 & 90,0 & 41,5 & 244,0 & 1,355 & 2,250 & 1,000 & 0,691 \\
\hline & 375,0 & 300,0 & 200,0 & 875,0 & & & & \\
\hline
\end{tabular}

cuadro

$4 \quad$ Solución histórica de Bortkiewicz

Coeficientes de transformación

\begin{tabular}{|c|c|c|c|c|c|c|c|c|}
\hline & K & V & $\mathrm{S}$ & $\mathrm{Q}$ & precios & $\mathrm{K}$ & V & $\mathrm{S}$ \\
\hline 1 & 288 & 96 & 96 & 480,0 & 1,352 & 1,280 & 1,067 & 1,029 \\
\hline 2 & 128 & 128 & 64 & 320,0 & 0,941 & 1,280 & 1,067 & 0,982 \\
\hline 3 & 64 & 96 & 40 & 200,0 & 1,111 & 1,280 & 1,067 & 0,964 \\
\hline
\end{tabular}

cuadro

$\underline{5} \quad$ Solución normalizada de Bortkiewicz
Coeficientes de transformación

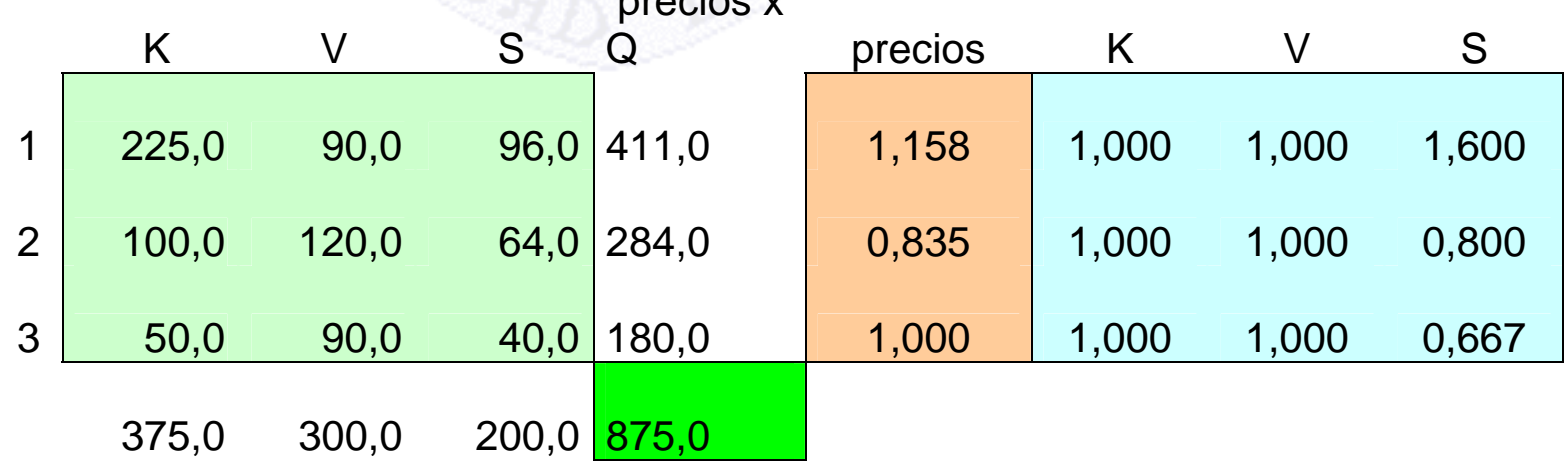

cuadro

$\underline{6} \quad$ Solución proporcional a las sumas

Coeficientes de transformación

precios $x$

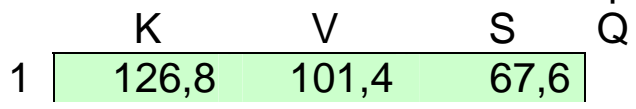

\begin{tabular}{c|ccc|} 
precios & $\mathrm{K}$ & $\mathrm{V}$ & $\mathrm{S}$ \\
\hline 0,833 & 0,563 & 1,127 & 1,127
\end{tabular}




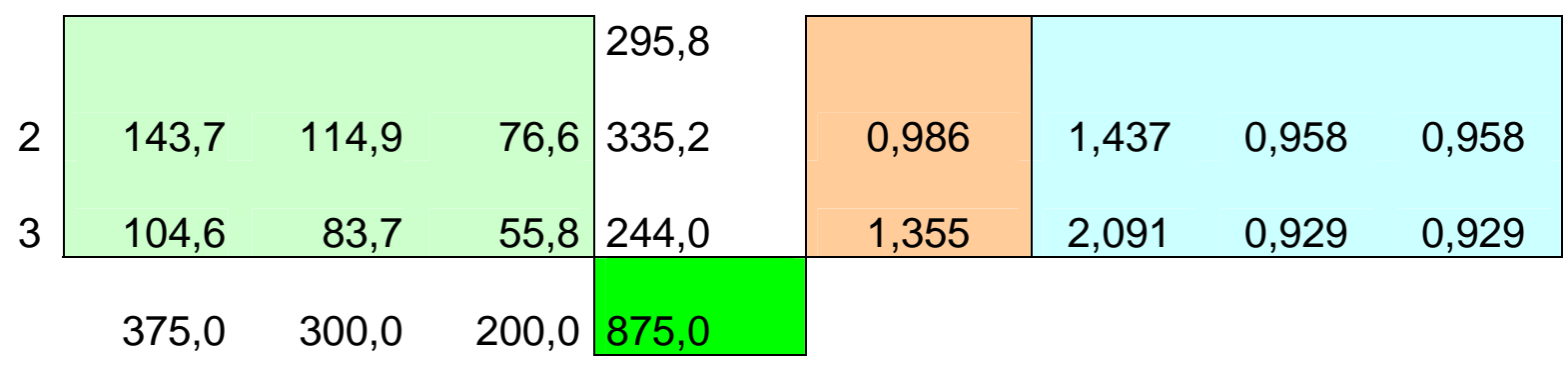

Los coeficientes de transformación son los cocientes entre los precios de los cuadros 2 a 6 y el cuadro 1 de valores.

Bibliografía

Afriat, S.: "Sraffa's Prices", Universitá degli Studi di Siena, quaderni 474. www.econ-pol.unisi.it/quaderni/474.pdf

Ahijado, M.: "Piero Sraffa: notas para una biografía intelectual", 1985, Centro de Estudios Universitarios Ramón Areces.

Bortkiewicz, L.: "Sobre la transformación de valores a precios en el tercer libro de "El Capital" de K. Marx", https://3794801810983261946-a1802744773732722657-s-

sites.googlegroups.com/site/revistacircus/Home/bortkiewicz_sobrelatransforma cion.pdf?attachauth=ANoY7crlJmuwc64DorHmHstfUVCjid0MpF32ejdwrX78r4V AO_bzPXgdPi340ubeCMRSI9zkIMRUoXzG9Z5OJs_h0C5CwIGsALOzJH_F9uo DXy2Gw6WZRH1gqqU2YLEsLsOWnOmh0ybtbhBAa2scAzDpO4fo81x8vN6SWKINwDwzs9VEFsWfWYljg-Ov3pmtg8CBgrLW3smZgNL-vUiySSu0EV9hvzDSTH4-74kP8B482Aw073sBc\%3D\&attredirects=0

Bour, Enrique A.: "Marx y la teoría económica moderna", 2007 http://www.aaep.org.ar/anales/works/works2007/bour.pdf

Caballero, A. y Lluch, E.: "Sraffa en España", Investigaciones Económicas (2a época, vol. X, n. ${ }^{\circ}$ 2), 1986.

Desai, M.: "Marxian Economic Theory", 1974 [Lecciones de teoría económica marxista, 1977, edit. Siglo XXI].

Dobb, M.: "The Sraffa system and the critique of neoclassical theory of distribution", 1970.

Dobb, M.: "Teoría del valor y de la distribución desde Adam Smith", edit. Siglo XXI editores.

Fiorito, Alejandro: "La implosión de la economía neoclásica". Está en la red: www.geocities.com/aportexxi/sraffa12.pdf 
Foncerrada, Luis Antonio: "Sraffa y Böhm-Bawerk". Está en la red: http://www.economia.unam.mx/secss/docs/tesisfe/FoncerradaPLA/tesis.pdf

Garegnani, P.: "El capital en la teoría de la distribución", 1982, ed. Oikos-Tau ("Il capitale nelle teorie delladistribuzone", 1982)

Garegnani, P.: "Heterogeneous Capital, The Production Function and the Theory Distribuction", 1970

Garegnani, P.:"Professor Samuelson on Sraffa and the Clasical Economists", The European Journal of the History of Economic Thought, 2007.

Garegnani, P.: "La realidad económíca", https://3794801810983261946-a-

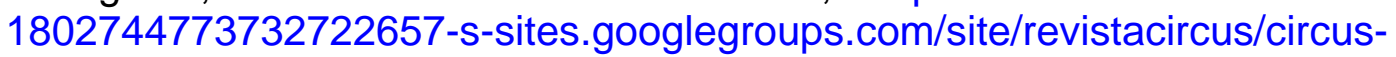
4/4garegnani.pdf?attachauth=ANoY7cpgiGWJTmh4MVt9ZM_ITxbEHEqOki_NSHxFeV4fYIMsh3RU13YECdk9WXJVh5mEhGbp8uDORKZkID24JeUBuTxaf6iL_EdbfNF3z-tkCG6-GO-juSq7N7c90auncfl2R4XU8Xn7WahPR6AWx7NgmPNc8lxVvC1xn7WKhBREovSyw9WB1JscB xEPAVi2gSNe1NCG3qQPhQqaoIN2iu4FzM5BUGg\%3D\%3D\&attredirects=0

Gehrke, Ch.y Kurz, D.: "Sraffa on von Bortkiewicz". Está en la red: http://www.newschool.edu/cepa/events/papers/050509_Bortkiewicz.pdf

Harcourt, G.C.: "Teoría del Capital" (Some Cambridge controversies in the theory of capital, 1975), apéndice al cap. 4, 1975, edit. Oikos-tau.

Keynes, J.M.: "Teoría General de la Ocupación, el Interés y el Dinero", FCE, 1992 (The General Theory of Employement, the Interest and Money, 1936).

Kurz, Pasinetti, Salvador y otros: "Piero Sraffa: The Man and the Scholar", Routledge, 2008.

Kurz y Salvadori: "Sraffa and the mathematicians: Frank Ramsey and Alister Watson", en "Piero Sraffa's Political Economy, edit Routledge,

Kurz, D. Heinz: "Critical Essays on Piero Sraffa's Legacy in Economics", 2000, Cambrigde University Press.

Kurz, D. Heinz; Salvadori, Neri: “Theory of Production”, 1997.

Kurz, Schefold, Salvadori: "Sraffa or an alternative economics", 2008, edt. Palmagrave Macmillan.

Marsahll, Alfred: "Principios de Economía, Fundación ICO, 2005 [Principles of Economy, 1890]

Marx, Carlos: "El método en la Economía Política", 1974, Ediciones Grijalbo, S.A.

Marx, Carlos: "El Capital", en el FCE, traducción de Wenceslao Roces.

Meek, R.: "Mr. Sraffa's Rehabilitationof Classical Economics", 1961.

Mendoza, Gabriel: "La transformación de valores en precios de producción", 1997

http://www.izt.uam.mx/economiatyp/numeros/numeros/10/articulos_PDF/10_2_ La_transformacion.pdf 
Mora Plaza, A.: "Sobre la transformación de valores a precios": http://www.eumed.net/ce/2009b/amp2.htm, http://revistas.ucm.es/cps/15786730/articulos/NOMA1010140379A.PDF

Mora Plaza, A.: "Notas sobre el teorema fundamental marxiano" http://www.eumed.net/ce/2009b/amp.htm, http://econpapers.repec.org/article/ervcontri/y_3a2009_3ai_3a200910_3a22.htm

Mora Plaza, A: "Descifrando a Sraffa”, Editorial Académica Española, 2011.

Morhisima, M.: "La teoría económica de Marx" (Marx's Economics, 1973), 1977, pág. 15, edit. Tecnos.

Moseley, F.: "El método lógico y el problema de la transformación". http://www.azc.uam.mx/publicaciones/etp/num7/a8.htm

Neri, Salvador: "Besicovitch, Sraffa and the existence of Standard Commodity", 2010:

http://host.uniroma3.it/eventi/sraffaconference2010/abstracts/pp_salvadori.pdf

Okishio, N.: "A mathematical note on marxian theorems", 1963.

Pasinetti. L.: "Critical of the neoclassical theory of growth and distribution". Está en la red: http://www.unicatt.it/docenti/pasinetti/pdf_files/Treccani.pdf

Pasinetti, L.: "Structural Change and Economic Growth: a theoretical essay on the dynamics of Wealth of Nations", 1981, Cambridge University Press.

Pasinetti, L.: "Rate of profit and income distribution in relation to the rate of economic growth", 1961/2.

Pasinetti, L.: "Switches of technique and the rate of return in Capital Theory", 1969.

Pasinetti, L.: "Crecimiento económico y distribución de la renta" ("Growth and Income Distribution", 1974), 1978, Alianza Editorial.

Pasinetti, L.: "Lecciones de teoría de la producción" ("Lezioni di teoria della produzioni", 1975), 1983, FCE.

Potier, J.P.: "Piero Sraffa", 1994, edicions Alfons Magnànim.

Ricardo, D.: "Principios de Economía Política y Tributación" (On the Principles of Political Economy and Taxation,), 1973, F.C.E.

Robinson, J.: "Ensayos críticos", 1984, Ediciones Orbis.

Roncaglia, Alessandro: "Piero Sraffa", Edit. Palgrave MacMillan, 2009.

Roncaglia, Alessandro: "La riqueza de las ideas", Prensas Universitarias de Zaragoza, 2009 ("The Wealth of Ideas. A History of Economic Thought", Cambridge University Press, 2005).

Roncaglia, Alessandro: "Sraffa and the Theory of Prices", 1978 [Sraffa e la teoria dei prezzi, 1975]

Samuelson, Paul: "Understanding the Marxian notion of Exploitation", 1971.

Schefold, Bertram: "Mr. Sraffa on Joint Production", 1971 
Schumpeter, J. A.: "Historia del Análisis Económico" (History of Economic Analisis, 1954), 1971, Ediciones Ariel.

Steedman, I.: "Marx, Sraffa y el problema de la transformación" (Marx after Sraffa, 1977), 1985, F.C.E.

Subiza Martínez, B.: "Juegos matriciales y su aplicación a la teoría PerronFrobenius", U. de Alicante; http://www.ine.es/revistas/estaespa/112_3.pdf

Sraffa, Piero: "Produción de mercancías por medio de mercancías" (Production of commodities by means commodities, 1960), 1975, Oikos-Tau.

Ricardo, D.: "Principios de Economía Política y Tributación" (On the Principles of Political Economy and Taxation,), 1973, F.C.E.

Vegara, J. M.: "Economía política y modelos multisectoriales",1979, edit. Tecnos.

Woods, J. E.: "The Production of Commodities. An Introduction to Sraffa", 1990, edit. MacMillan,. 